\title{
Exploitation of force displacement curves in blanking-feature engineering beyond defect detection
}

\author{
Christian Kubik $^{1}$ (i) $\cdot$ Johannes Hohmann ${ }^{1} \cdot$ Peter Groche ${ }^{1}$ \\ Received: 1 August 2020 / Accepted: 1 December 2020 / Published online: 22 January 2021 \\ (C) The Author(s) 2021
}

\begin{abstract}
With the current tendency of mass production towards customer-oriented serial production, blanking processes are facing new challenges. They require an increase in knowledge about faulty process conditions and their influence on the quality of a component as well as an instruction for a target-oriented adaptation of the process. The aim of this study is therefore to identify property deviations based on force-displacement curves and to establish correlations between the quality of the component and features of force-displacement curves. For this purpose, parameter variations are carried out on a high-speed press and features are extracted from these measured time series. Afterwards, the correlation between varying process parameters and features is carried out to obtain a conclusion about the condition of the component. The results of these studies for a regression analysis form the basis for a decision support system to identify deviations of the component as well as faulty process conditions. The paper shows that a reliable correlation between the quality of the component and force-displacement curves is possibly based on the feature engineering approach even under industrial boundary conditions. This also applies to the simultaneous modification and variations within a limited range of several process parameters.
\end{abstract}

Keywords Blanking $\cdot$ Supervision $\cdot$ Feature engineering $\cdot$ Fault detection

\section{Introduction}

Blanking is one of the most commonly used operations in the sheet metal forming industry and enables the manufacturing of a variety of complex components [1]. Due to its reduced manufacturing costs and stable qualities even at high production rates, blanking has frequently replaced other manufacturing processes such as forging or casting over the past decades. This trend will continue and global sales of blanking are predicted to reach USD 299.6 billion by 2025 [2]. The recent shift towards shorter product lifecycles and the progressive evolution of mass production towards customer-oriented serial production, along with a rise in production rates, is posing major challenges for sheet metal working [3, 4]. Increasing overall time required for troubleshooting and process optimization is one of the main challenges. Especially, blanking processes,

Christian Kubik

kubik@ptu.tu.darmstadt.de

1 Institute for Production Engineering and Forming Machines, Technische Universität Darmstadt, Otto-Berndt-Straße 2, 64287 Darmstadt, Germany which are characterized by high rates of production and process-related complexity as well as a strong dependence on empirical knowledge and manual skills, are affected by the new requirements. Therefore, one of the key challenges for blanking technology is to control complexity by supporting personnel and improving process control based on real-time data.

One way to master this complexity and to support qualified personnel in process control is assistance systems. These types of systems are generally developed in three stages: data acquisition, data analysis, and assistance in adjusting the process (data utilization) [5]. In relation to conventional monitoring systems, which only identify faulty process conditions when an error has actually occurred, process-driven assistance systems detect even minor differences in the current condition of the process, identify the cause for a difference, and provide personnel with guidance. This allows prompt adjustments to the process to ensure the required component quality and protection of tools and machinery. Assistance systems that continuously analyze both direct (e.g., process forces during blanking) and indirect (e.g., motor power of the press) data are still not state of the art today. This is because these systems require extensive models in which human cognitive abilities 
are combined with data-driven approaches. Especially in sheet metal forming, little work has been done on process-driven assistance systems which support personnel in decision making and implementation of process optimizations based on sensor data and process specific models. This is probably due to the complexity of these processes caused by a high number of control and disturbance variables as well as required domain-specific expertise $[6,7]$.

\subsection{The blanking process}

As shown in Fig. 1, a blanking process can be divided into three phases according to the force-displacement curve [8]. In the punch-phase (I), the punch impacts on the sheet metal and starts to elastically deform the material. If the stresses that occur exceed the maximum shear strength of the material, it tends to deform plastically. When the shearing stress finally exceeds the shear fracture limit, the material tears and the stored elastic energy is abruptly released. In the following push-phase (II), the component or the grid-shaped discard is completely pushed out of the die and the punch passes through the bottom dead center. Finally, the punch is pulled out of the

\section{a) force-displacement curve of blanking process}

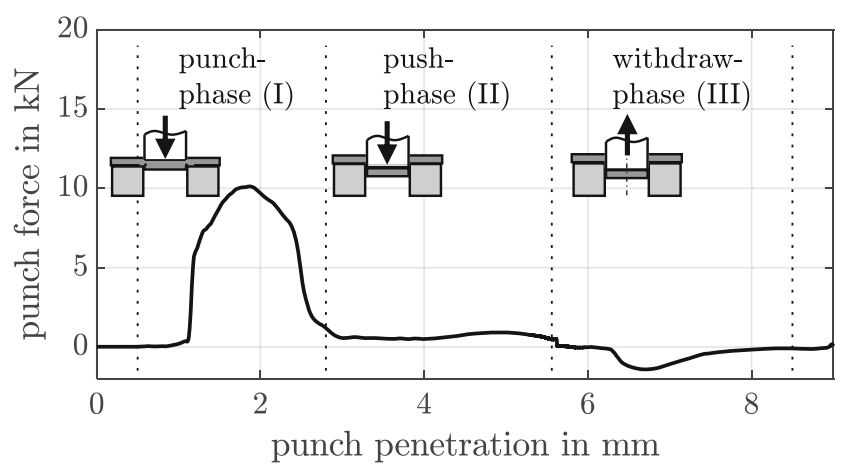

b) partition the cutting edge surface

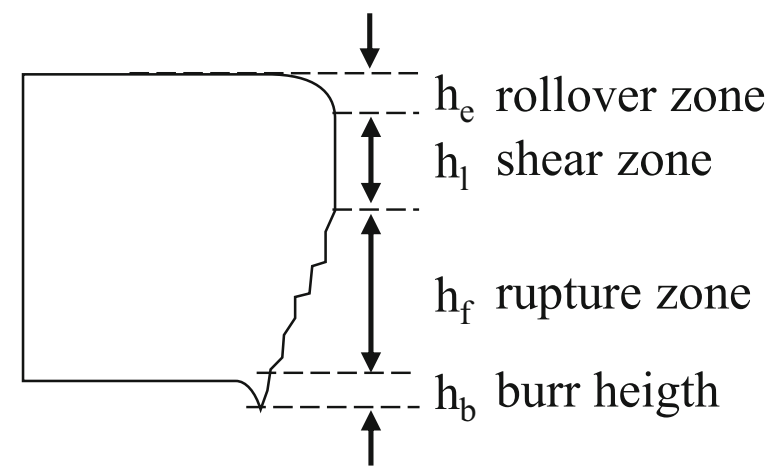

Fig. 1 Force-displacement curve [8] (a) and partition of the cutting edge during blanking of sheet metals into characteristic areas [9] (b) die in the withdraw-phase (III) and withdrawal forces occur as a result of jamming between the sheet and the punch.

The maximum blanking force during the punch phase (I) represents a crucial factor in dimensioning the blanking tool and designing the blanking operation. According to Lange, the maximum force is defined as the product of the shearing resistance $k_{\mathrm{S}}$, the cutting length $l_{\mathrm{S}}$, and the sheet thickness $s$ :

$F_{\mathrm{S}, \max }=l_{\mathrm{S}} \cdot s \cdot k_{\mathrm{S}}=A_{\mathrm{S}} \cdot s$

This results in the shearing resistance:

$k_{\mathrm{S}}=\frac{F_{\mathrm{S}, \max }}{A_{\mathrm{S}}}$

The shearing resistance is defined as the quotient of the maximum blanking force $F_{\mathrm{S} \text {, max }}$ and the cross-section $A_{\mathrm{S}}$. It is neither a constant nor a material property but depends on several variables such as tool parameters (clearance, tool wear, surface condition of the cutting elements), the geometry of the blanked part (cutting line contour, open or closed cut, sheet thickness), and other parameters (lubrication, tensile strength, tool and work piece temperature, cutting speed) [1,9]. The tensile strength of the sheet material has the most significant influence on the shearing resistance. This is due to the shear forming process taking place during the cutting process. In order to consider further effects on the shear resistance, an empirically determined coefficient $\mathrm{c}$ is introduced. In literature, this value ranges $0.5-0.9$ depending on the prevailing boundary conditions of the process $[10,11]$.

Due to variations of the parameters, a product deviation occurs at the cutting edge of the punched component (see Fig. 1a). This deviation, also referred to as form error, is a crucial indicator of the quality of the components. The form error found on the blanked surface is divided into rollover zone $h_{\mathrm{e}}$, shear zone $h_{1}$, and rupture zone $h_{\mathrm{f}}$. In addition, the burr height $h_{\mathrm{b}}$ is a key indicator of a poor quality of the component. It is directly influenced by the wear state and reflects the current tool condition [12]. Increasing the burr height causes injury when handling the components and requires expensive post-processing [13].

\subsection{Influencing parameters during blanking}

The quality and accuracy of the resulting component are affected by the parameters shown by the Ishikawa diagram in Fig. 2. The scientific literature defines more than forty different parameters that influence the blanking process. As shown in Fig. 2, these can be classified into four categories: semifinished product properties (Material), condition and setup parameters (Process), press performance (Machine), and process-related parameters (Tool) $[14,15]$. Consequently, the various properties of the component are faced with a variety of parameters, which drastically complicates reliable 


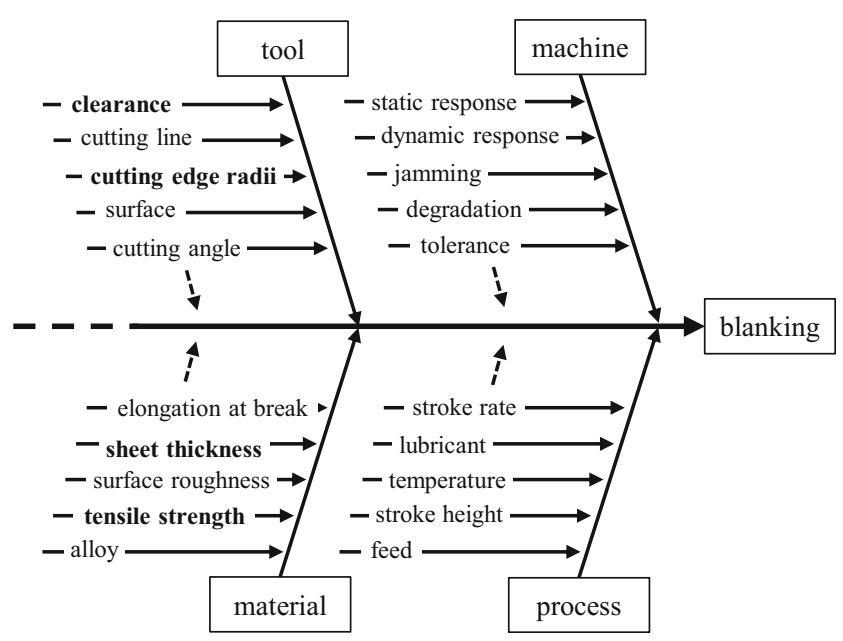

Fig. 2 Parameters affecting the quality of the component in blanking [9]

process control and a detailed physical understanding of the process. Even minor process adjustments can significantly influence the percentage distribution of the areas as shown in Fig. 1 [16].

In recent years, numerous studies have investigated the influence of these process parameters on product quality. Particularly, critical parameters, such as the clearance [17], the cutting line [18], and the cutting edge radii [19] which change during the process as a result of progressive wear, are part of these studies.

Also, research on manufacturing related uncertainties within one coil batch regarding the geometry (sheet thickness) and the mechanical properties of the semi-finished products (tensile strength) was investigated [20]. However, these investigations are mainly limited to the correlations between these critical process and system parameters or the quality of the components. Correlations between process parameters und measured process variables (e.g., force, acceleration) to describe the quality of the components are only rarely the subject of current investigations.

\subsection{Monitoring of property deviations}

Diagnostic analysis of property deviations refers to the detection, isolation, and identification of faulty process conditions. Investigations on diagnostic monitoring primarily focus on the detection of correlations between process variables and abnormal process conditions. In most cases, force sensors are therefore integrated within the tool $[21,22]$. The findings of these investigations primarily apply to the protection of machines and tools and define thresholds and envelopes where a decision is made between acceptable and harmful conditions [23, 24]. Furthermore, classification and pattern recognition techniques are used to detect faulty process conditions. This classification of signals is carried out by statistical methods, artificial intelligence, and model-based approaches.
Features are served to establish a basis for identification of property deviations, which are then used for classification, modelling or correlation analysis. For this problem, the socalled feature engineering (process-driven) and feature extraction (data-driven) approaches are suggested in the literature. In feature extraction, the identification of characteristic values from data sets is carried out by statistical methods, such as principal component analysis (PCA) or support vector machines (SVM) [25], wavelet transformations [26], or stochastic models [27]. However, only discrete error patterns can be detected and decisions between acceptable and nonacceptable process conditions can be made [28]. By contrast, in feature engineering, the extraction of characteristic values is carried out by the domain-specific knowledge engineers [8]. For this purpose, manually defined rules and algorithms are established. These rules can base on physical laws, empirical observations, or experimental findings. This process-driven approach has the advantage of using domain-specific knowledge for data acquisition and analysis to determine features. In contrast, data-driven approaches to extract characteristic values are dependent on the available data [29]. Although these advantages are obvious, there is little available research on the process-driven feature engineering approach.

In addition to this feature engineering approach, limited research is conducted for systematical investigations between varying process parameters and force signals. In particular, deviations within a few percent of the reference state, as they occur in industrial processes, are not the subject of recent studies $[8,30,31]$. Furthermore, most papers focus on sheet metal forming for general applications with low stroke rates $(<$ $50 \mathrm{spm}$ ), where no material breakage occurs, compared with the blanking process. Dynamic effects resulting from material separation are therefore negligible. In stamping processes, however, stroke rates of sometimes well over $1000 \mathrm{spm}$ are used, which leads to short tool engagement times at complex stresses and strains $[6,21]$. Analyzing these cutting processes at high stroke rates by recording process forces therefore requires special demands on the measurement equipment and the interpretation of the signals [32]. The analysis of correlations between force signals and varying process parameters and their effect on the quality of the component at stroke rates above $50 \mathrm{pm}$ is rarely part of published investigations. Instead, these investigations are limited to the acquisition of forces at different stroke rates $[33,34]$.

The current state of research therefore leads to the conclusion that a systematic investigation of the correlations between process parameter variations, force-displacement signals, and quality features of the produced component is not yet available. Therefore, the aim of this work is to establish correlations between force-displacement curves and the quality of the component for critical process parameters under industrial conditions. Based on the correlations, property deviations can be identified and the process control can be managed by 
personnel. For this purpose, the experimental setup is explained in Section 2 and methods for process-driven extraction features are presented. Following this, in Section 3, results of correlations between varying features, determined from forcedisplacement signals and quality of the component, are presented. Correlations between single process parameters and features are taken into account. In Section 4, the principles for a realization of a decision support system for the detection of property deviations and the detection of faulty process conditions (component or tool) are given. Finally, in Section 5, the detection of the property deviations is explained by means of a typical defect in the process (wear of the cutting edge radii). It is shown that a detection of the property deviations is even possible if several parameters are varied simultaneously. By extending the features values derived from the pushand withdraw-phase, the accuracy of identifying the property deviations is significantly increased.

\section{Analysis of the force-displacement curves during blanking}

\subsection{Experimental setup und measurement}

The experimental data were performed on a mechanical highspeed press from Bruderer AG (BSTA 810). The machine allows a nominal force of $810 \mathrm{kN}$ and stroke rates of up to $1000 \mathrm{spm}$ at a stroke height of $16 \mathrm{~mm}$. The number of strokes for carrying out the tests was $300 \mathrm{spm}$, and a stroke distance of $35 \mathrm{~mm}$ was set. As shown in Table 1, a cold-rolled steel (1.0347) and a high-strength steel (Rawael $\left.{ }^{\circledR} 80\right)$ were used for the experiments.

The recording and evaluation to investigate correlation between force-displacement curves and the quality of the components follow the procedure shown in Fig. 3.

In order to analyze the influence of varying process parameters on blanking, artificial detunings are first introduced. These are set by specific adjustments to the tools and semifinished products listed in Table 2. A large number of studies have shown that the critical parameters that can change during the process are caused, on the one hand, by tool wear and, on the other hand, by fluctuations in batch quality during the manufacturing process of the semi-finished products.

Tool-sided variations of the parameter are caused by abrasive and adhesive wear of the tool. This leads to a change in the tool geometry, which results in variations of the clearance
$C_{\mathrm{i}}$ (flank wear) and the cutting edge radii $r_{\mathrm{i}}$ (face wear) [35, 36]. On the semi-finished product side, variations in sheet thickness $s_{\mathrm{i}}$ and tensile strength $R_{\mathrm{i}}$ occur as a result of the manufacturing process. While the sheet thickness within a coil can vary by up to $\pm 5 \%$, variations of up to $\pm 15 \%$ occur in tensile strength $[30,31]$. These critical parameters are varied within the limits occurring in the process (see Fig. 4). For this purpose, the tool-side variations of the cutting edge radii and clearance are realized by replacing individual tool components. The tool consists of a head and base plate, which are guided by four columns. During the movement of the punch from the top dead center to the bottom dead center, the punch impacts the material and penetrates it. In the course of the further downward movement, the part is pushed out of the die. During the reverse stroke, the punch is then pulled out of the die and the sheet metal is removed from the punch by the stripper plate.

All investigations were conducted on a high-speed press with the experimental setup shown in Fig. 5. For measuring force-displacement curves, a uniaxial piezo-electrical force washer (Kistler 9054A) with a nominal force of $30 \mathrm{kN}$ was integrated in the direct force flow of the upper tool. In addition, the cutting forces are recorded in the lower tool by three triaxial force piezo-electrical force washers (Kistler 9047C) with a nominal force of $80 \mathrm{kN}$. The symmetrical arrangement of the sensors allows the cutting force to be spatially resolved. The charge distribution resulting from a change of the load on the force washers is converted into a voltage signal by a charge amplifier (Kistler 5073A). An eddy current sensor (Micro-Epsilon EU8) is used to record the displacement. The voltage signals of the force sensors and the laser are recorded by a CompactRIO with integrated measuring modules (NI 9222 and NI 9223). The force washer and the charge amplifier were calibrated according to DIN EN ISO 376 prior to their application. [37]. Since the blanking process is strongly influenced by the dynamic effects resulting from the high stroke rates, the setting of the sampling frequency has to be set high enough. The required sampling frequency depends on the selected stroke rate. Figure 6 shows the complete $360^{\circ}$ stroke cycle $\varphi_{0}$ of the Bruderer press from top dead center to bottom dead center back to top dead center. The actual tool engagement time only takes place in a limited angular range $\varphi_{\text {punch. }}$. With an assumed stroke frequency of $300 \mathrm{spm}$ and an angular range of 160 to $200^{\circ}$, this results in a time of $0.1 \mathrm{~s}$ while the tool is in contact with sheet metal. As the tool engagement time is further divided into the three phases (see Fig.
Table 1 Properties of the material used for the experiments

\begin{tabular}{llll}
\hline Material & Tensile strength in MPa & Elongation at break in \% & Percentage of carbon (vol\%) \\
\hline Rawael ${ }^{\circledR} 80$ & $936.6 \pm 3.3$ & $8.6 \pm 0.2$ & 0.041 \\
1.0347 & $299.8 \pm 2.9$ & $34.7 \pm 1.3$ & 0.100 \\
\hline
\end{tabular}


Fig. 3 Procedure of investigations for establishing a regression analysis, which is a basic algae for the identification of component quality in case of varying process conditions during blanking feature

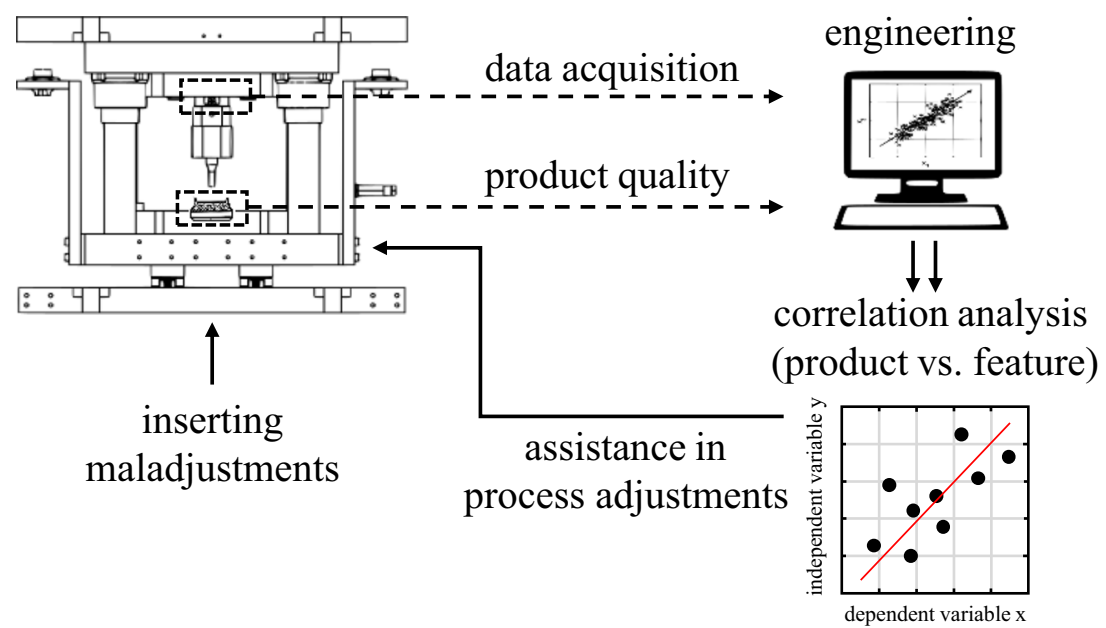

1), a time window of $50 \mathrm{~ms}$ results for the punch-phase. In order to be able to continue processing the dynamic effects under these circumstances, a sampling frequency of $f_{\mathrm{s}} 90 \mathrm{kHz}$ was selected. To keep the amount of data as small as possible, only a part of the entire stroke is recorded. Therefore, data recording starts if the tool passes an inductive proximity sensor. During the reverse stroke, the tool again passes past the inductive proximity sensor and the measurement is stopped. This finally results in a measuring range $\varphi_{\text {trigger }}$ of 140 to $220^{\circ}$ or punch penetration of $9 \mathrm{~mm}$.

In order to obtain a statement about the current quality state of the component based on the cutting edge surface characteristics (Fig. 1), a measurement of the component contour is necessary. For this purpose, the punched parts are embedded in resin and afterwards cross-sectional micrographs of the specimens are created. The micrographs were finally analyzed with a digital microscope. To calculate the individual percentages of the cutting edge surface characteristics, the measured length of each characteristic area of the blanked part and the initial thickness of the sheet metal are divided.

\subsection{Feature engineering}

Literature has shown that qualitative differences within force-displacement curves caused by varying boundary conditions of the process can be determined [21,22]. However, it is not possible to conclude property deviations from these variations or their influence on the quality of the component. The conclusions are limited to the distinction between acceptable and unacceptable process conditions $[23,38]$. In order to be able to quantify the current process conditions from the force-displacement curves and to determine the property deviations in the case of occurring unacceptable process conditions, features are identified [39]. The aim of feature engineering is to reduce the degree of dimensionality of the data and to select relevant features that explicitly describe the process state. On the basis of the process-driven approach used in this paper, characteristic values are extracted by feature engineering. Based on the existing domain knowledge, engineering algorithms are developed to extract features from the force-displacement curves.

The feature engineering used in this paper is based on the results of Hohmann et al., Hoppe et al., and Übelacker and is shown in Fig. $7[40,41]$. The force signal is initially divided into three phases. Here, characteristic points are identified which define the respective start and end points as well as extrema during each phase. Finally, the features in each phase can be determined from these characteristic points. These features include length of the phases $l_{\mathrm{j}, \mathrm{i}}$, maximum forces $F_{\mathrm{j}, \mathrm{i}}$, work done $W_{\mathrm{j}, \mathrm{i}}$, and starting point of the phases $S_{\mathrm{j}, \mathrm{i}}$. Additionally, the elastic gradient of the punch-phase $\delta_{\mathrm{p}, \mathrm{i}}$ is defined. In this case, the index $j$ describes the respective phase of the cutting process (punch-phase (p), push-phase (pu),
Table 2 Critical parameters that significantly influence the blanking process

\begin{tabular}{ll}
\hline Process parameters & Variations \\
\hline Cutting edge radii $r_{\mathrm{i}}$ & Sharp (ref.), $0.1 \mathrm{~mm}, 0.3 \mathrm{~mm}, 0.5 \mathrm{~mm}$ \\
Clearance $C_{\mathrm{i}}(1.0437)$ & $3.75 \%, 7.50 \%$ (ref.), $11.75 \%$ \\
Tensile strength $R_{\mathrm{i}}$ (Rawael® 80) & $910 \mathrm{MPa}$ (ref.), $900 \mathrm{MPa}, 855 \mathrm{MPa}, 790 \mathrm{MPa}$ \\
Sheet thickness $s_{\mathrm{i}}$ & $2.01 \mathrm{~mm}($ ref.), $1.94 \mathrm{~mm}, 1.87 \mathrm{~mm}, 1.83 \mathrm{~mm}$ \\
\hline
\end{tabular}




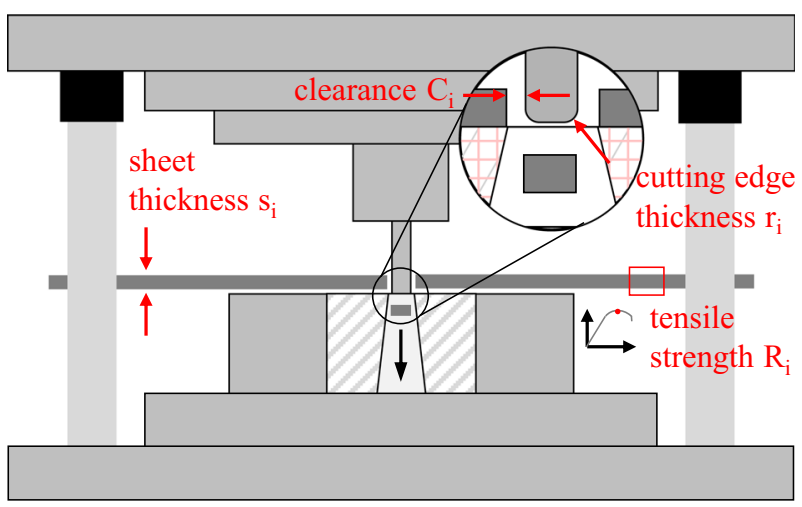

Fig. 4 Critical parameters that significantly influence the blanking process shown in the experimental tool

withdraw-phase (w)), and $i$ the number of variations in the experiments.

These features allow the detection of variations in the semifinished material and tool parameters. Thus, the maximum force is directly influenced by material properties, tool, and process parameters as well as the geometry of the blanked part. In contrast, the elastic gradient mainly depends on the mechanical properties (tensile strength and sheet thickness) of the semi-finished product. In addition, this increase of the gradient is influenced by geometric changes in the forming zone caused by a rounded cutting edge radii or an enlarged clearance. In this case, the sheet metal responds similar to a bending beam, which is supported at the edges of the die. As

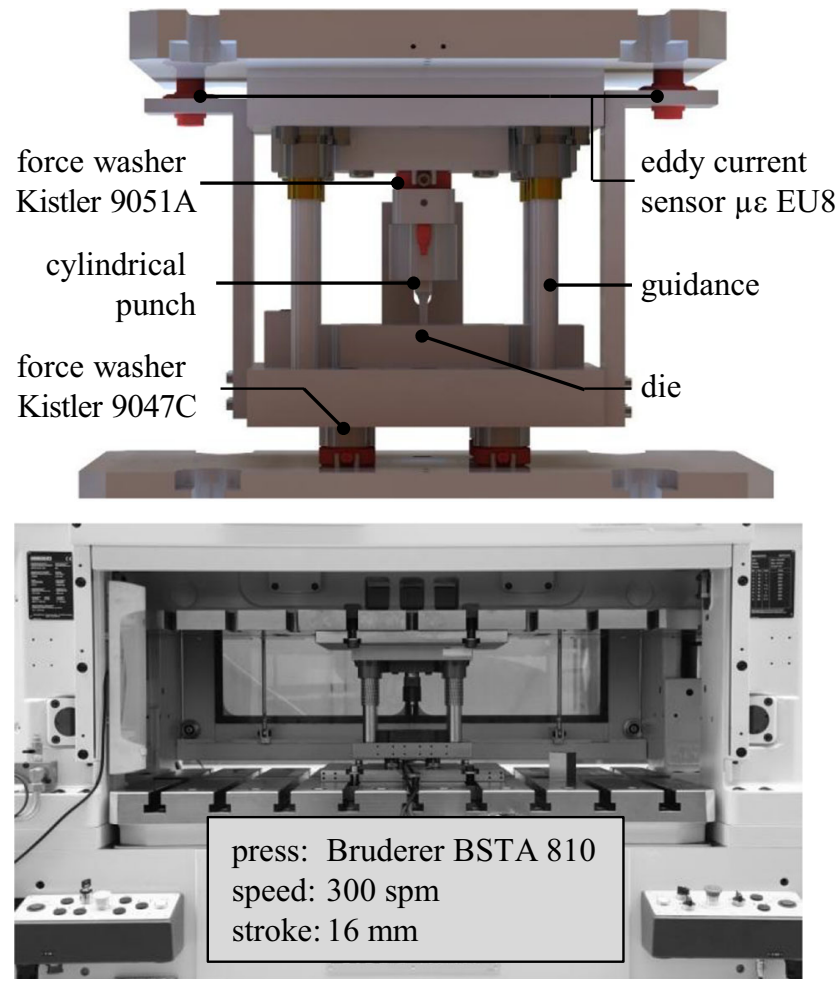

Fig. 5 Sectional view of a multisensory blanking tool the clearance increases, the length of the beam which has no contact with the face of the punch increases. This effect is also shown by rounded cutting edge radii. In the worst case scenario of a clearance $C_{\mathrm{i}}=0$ the rise of the process force only depends on the material properties of the sheet metal and the constant overall stiffness of tool and press (see Fig. 8a). If the clearance $C_{\mathrm{i}} \neq 0$, the length of the beam which has no contact to the face surface of the punch increases. This causes a deflection of the sheet metal which is superimposed to the actual stiffness of the sheet metal. Based on this effect, a reduced slope of the process force is observed and consequently the elastic gradient decreases. Figure 8 shows the geometric dimensions in the region of the forming zone with an increased clearance and cutting edge radii.

Variations of tool parameters such as clearance, which decreases due to adhesive wear, will increase frictional forces between punch and sheet metal. This increases the work in the push-phase (II) and withdraw-phase (III). Correlations between these features and variations in process parameters can be related to physical phenomena in the process, however, they require domain knowledge.

Features investigated in this paper refer to the four values, length of phase $l_{\mathrm{p}, \mathrm{i}}$, elastic gradient $\delta_{\mathrm{p}, \mathrm{i}}$, maximum force $F_{\mathrm{p}, \mathrm{i}}$, and work $W_{\mathrm{p}, \mathrm{i}}$ done during the different phases $\mathrm{j}$. Using features from the push- and withdraw-phase also offers the opportunity to increase the informative value of the forcedisplacement curves.

\section{Correlation analysis between features and quality of the component}

In order to identify the influence of varying punch and semifinished product parameters and to quantify the respective influence on the quality features of the component, the parameters clearance $C_{\mathrm{i}}$, cutting edge radii $r_{\mathrm{i}}$, tensile strength $R_{\mathrm{i}}$, and sheet thickness $s_{\mathrm{i}}$ will be varied in experiments. Variation of the process parameters has been set within industrial limits, ensuring that the reliability of the results is maintained even at minor variations. Therefore, the parameters defined in Fig. 4 are considered for the later regression analysis. To statistically validate the results, the experiments were replicated 50 times for each varied parameter. In case of this scenario, 200 forcedisplacement curves are obtained for each feature of all varied parameters. Figure 9 shows an exemplary representation of the measured time signals for the varied parameter cutting edge radii. Afterwards, the features for each forcedisplacement curve were determined algorithmically. Finally, the mean value and the standard deviation for a parameter variation were derived from these 50 features. A confidence interval of $95 \%$ was assumed for the calculation of the standard deviation. 
Fig. 6 Cutting phases during which the punch is in contact with the sheet metal (a) shown for a complete stroke cycle (b) a)

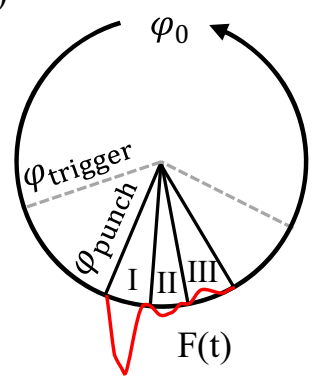

b)

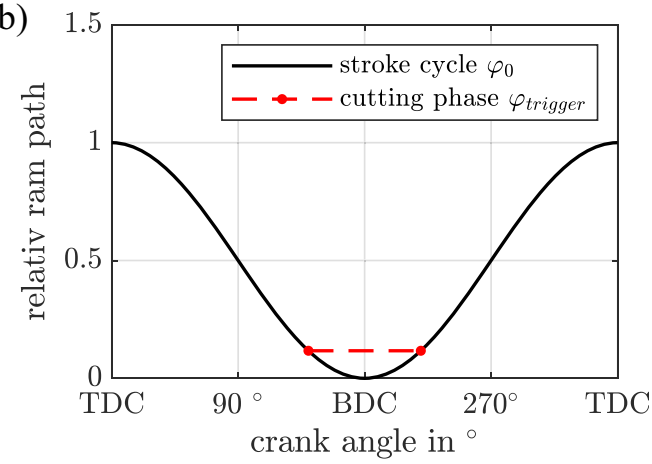

\subsection{Clearance}

For various values of the clearance, force-displacement curves are shown in Fig. 10. It can be seen that a reduction of the clearance results in an increase of the maximum process force. In addition, an increase in the length of the punch-phase can be observed, confirming the investigations in literature $[42$, 43].

Figure 11 shows the influence of a reduced clearance on the features. An increase can be observed for the maximal force, the length of the phase and the work done. This is caused by the fact that with increasing clearance, the shearing resistance $k_{\mathrm{S}}$ decreases and thus the maximum force decreases [9]. In addition, reduced clearance results in stresses close to the cutting edge of the punch. Thus, small clearances create stresses where Mohr's circle is shifted in the direction of higher compression. This leads to a shift of the shear fracture limit towards higher values and enlarged plastic deformation of the material. Due to the reduced clearance, the deflection of the sheet metal inside the die is prevented and a fast increase of process force is noticeable (Fig. 8). Because of dynamic effects caused by different masses in the upper and lower tool, which are superimposed on the force-displacement curve, there is a standard deviation in the description of the elastic gradient [32,34]. Therefore, it has to be assumed that within the range of elastic deformation of the force-displacement

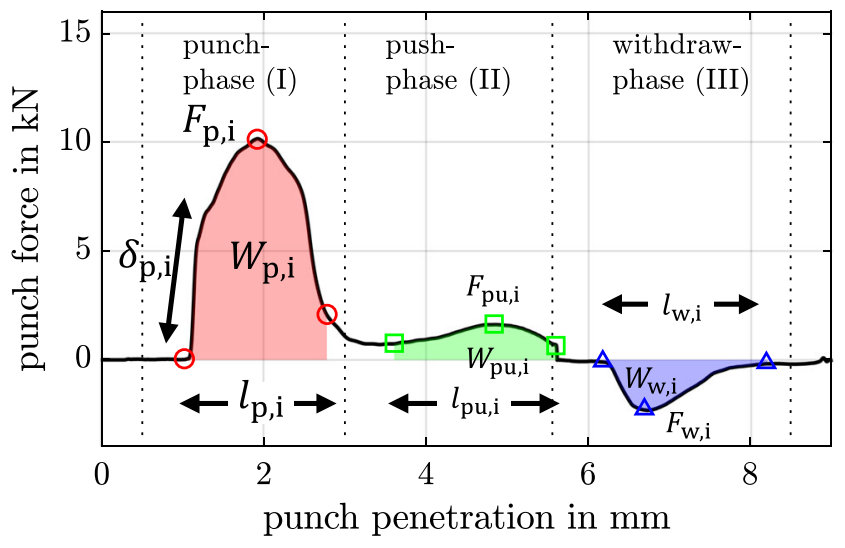

Fig. 7 Features extracted from force-displacement curves [8, 40] curve, the influence of clearance is overlaid by dynamic effects. This will result in a reduced reliability of the elastic gradient as a feature. In Fig. 11, this can be seen from the error bars of the elastic gradient. Due to the reduced reliability, the clearance is not clearly determined when the gradient is considered separately.

The results of the feature engineering analysis are also reflected in the geometry of the cutting edge. Figure 12 shows the influence of clearance on the percentage by area of the cutting edge. An extended punch-phase as consequence of a reduced clearance correlates with the increase in the shear zone $h_{1}$. Furthermore, an increase of clearance leads to an increased rollover zone $h_{\mathrm{e}}$.

\subsection{Cutting edge radii}

The force-displacement curves shown in Fig. 13 reflect the wear-related chamfering of the cutting edge. It can be seen that the length of the punch-phase and the maximal punch force increase with rising cutting edge radii [33].

Figure 14 shows the influence of the cutting edge radii on the features. As a result of increasing cutting edge radii, the stress peaks are applied to the shearing zone with a delay. In this procedure, the material initially covers the punch contour, so that the actual cutting process is superimposed by a process similar to stretch- or deep-drawing. Due to the rounding of the cutting edge radii, stress peaks are reduced, cracks are initiated later, and plastic flow of the material is extended. This leads to an elongation of the punch-phase which results in an increase of work done in this phase. On the other hand, the elastic gradient decreases with increasing cutting edge radii. For large radii, there is a reduced cutting line and thus a larger clearance at the moment when the punch hits the material. Similar to Section 3.1, a larger cutting edge radii increases the free span length of the sheet metal in the die, which results in a reduction of the elastic gradient (Fig. 8b). Also, in this case, dynamic effects are superimposed on the elastic rise of the force, resulting in a higher variance of the features.

Looking at the characteristics of the cutting edge surface of the component, a shift from the rupture zone to the shear zone can be observed (Fig. 15). On the other hand, the rollover zone 
Fig. 8 Influence of geometric parameters on the elastic gradient in the forming zone.a increased clearance $\mathrm{C}_{\mathrm{i}}$, b increased cutting edge radii $r_{i}$
a) increased clearance $\mathrm{C}_{\mathrm{i}}$
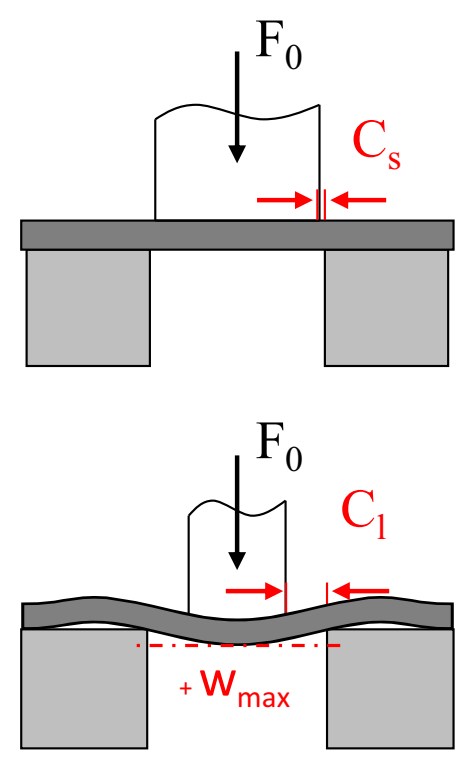

b) increased cutting edge radii $r_{i}$
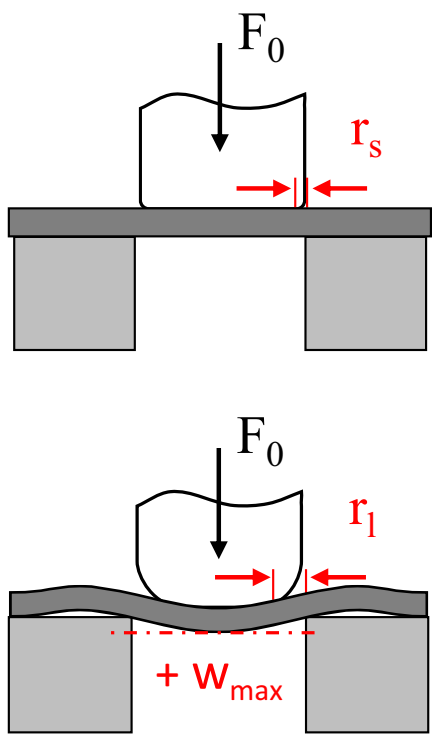

is changed only slightly. These results correspond to the features extracted in Fig. 14. With increasing cutting edge radii, the plastic deformation of the material is extended and results in an increase of the punch phase and as a consequence in an increase of the shear zone. At the same time, the burr height also increases significantly. These results confirm the correlation between the burr formation and the wear condition. The higher the wear on the cutting edge, the higher the burr [44, 45].

\subsection{Sheet thickness}

The force-displacement signals of the measurements are shown in Fig. 16 for the variation in sheet thickness of the semi-finished material. It can be seen that a delayed start of the cutting phase $S_{\mathrm{i}}$ occurs with decreasing sheet thickness $S_{\mathrm{i}}$. Compared with the starting point of the initial sheet thickness

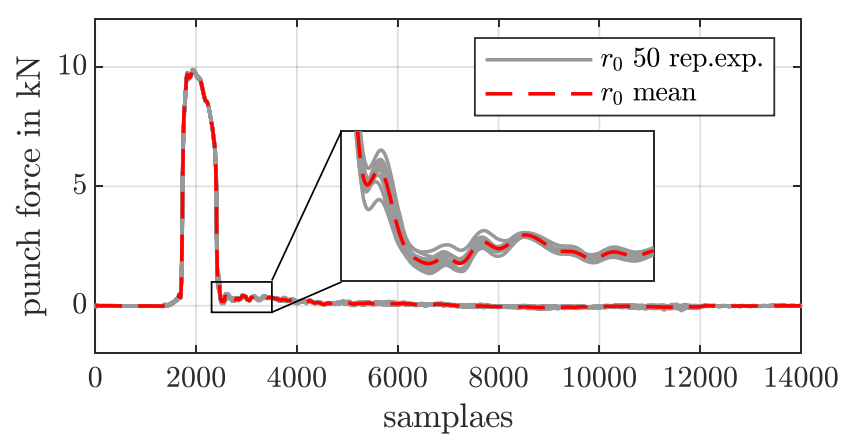

Fig. 9 Exemplary representation of the replicated experiments to determine features from force-displacement curve of parameter cutting edge radii
$S_{0}$, the force-displacement curves shift towards the bottom dead center.

Figure 17 shows the influence of sheet thickness variations on the features. As expected, the maximal punch force decreases with decreasing sheet thicknesses, which correspond to the analytical relationship according to Doege and Behrens [46]. They assume a linear dependence of the maximum cutting force and the sheet thickness. As a result of the decreasing punch force and the length of the punch-phase, a significant reduction of the work done in the punch-phase results. Furthermore, the elastic gradient decreases with a reduced sheet thickness. The increased sheet thickness results in a reduced deflection of the sheet in the die. Similar to the reduction of clearance, the force increases immediately after the punch has made contact with the sheet. This results in a faster rise of the process force and thus an increased value of the elastic gradient. Similar to a double-sided supported beam, the moment of resistance of the beam is reduced by thinner sheets.

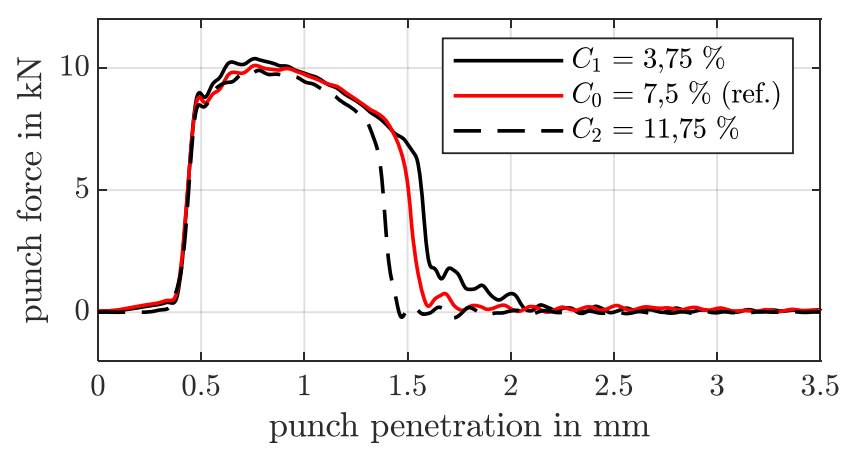

Fig. 10 Force-displacement graph for varying parameter clearance $C_{\mathrm{i}}$ 
Fig. 11 Features of the punchphase depending on clearance $C_{\mathrm{i}}$ for maximal force $F_{\mathrm{p}, \mathrm{i}}(\mathbf{a})$, work done $W_{\mathrm{p}, \mathrm{i}}(\mathbf{b})$, length $l_{\mathrm{p}, \mathrm{i}}(\mathbf{c})$, and elastic gradient $\delta_{\mathrm{p}, \mathrm{i}}(\mathbf{d})$

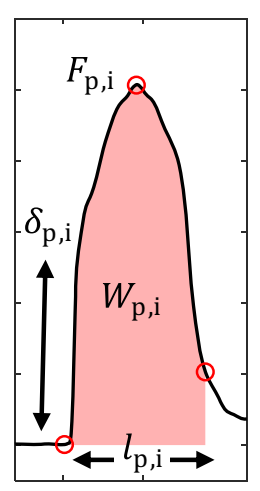

By identifying the start point $S_{\mathrm{i}}$ of the cutting phase, the current sheet thickness could be determined using the forcedisplacement curves. Table 3 shows in the first column the manually measured sheet thickness difference in relation to the starting sheet thickness $S_{0}$ of $2.01 \mathrm{~mm}$. Considering the uncertainties of measurement and manufacturing-related tolerances, the technical measurement accuracy is $\pm 0.003 \mathrm{~mm}$. Column 2 shows the difference of the starting point of the punch-phase $\Delta S_{\mathrm{i}}$, derived from the force-displacement curve. Finally, column 3 shows the variance of sheet thickness calculated from features. Based on this, it is evident that sheet thickness variations in the range of $\pm 0.0262 \mathrm{~mm}$ can be detected with the present measurement setup.

Even though obvious trends can be seen in the features, the results of the microsection show no significant variations in the geometry of the cutting edge (Fig. 18). This is because the

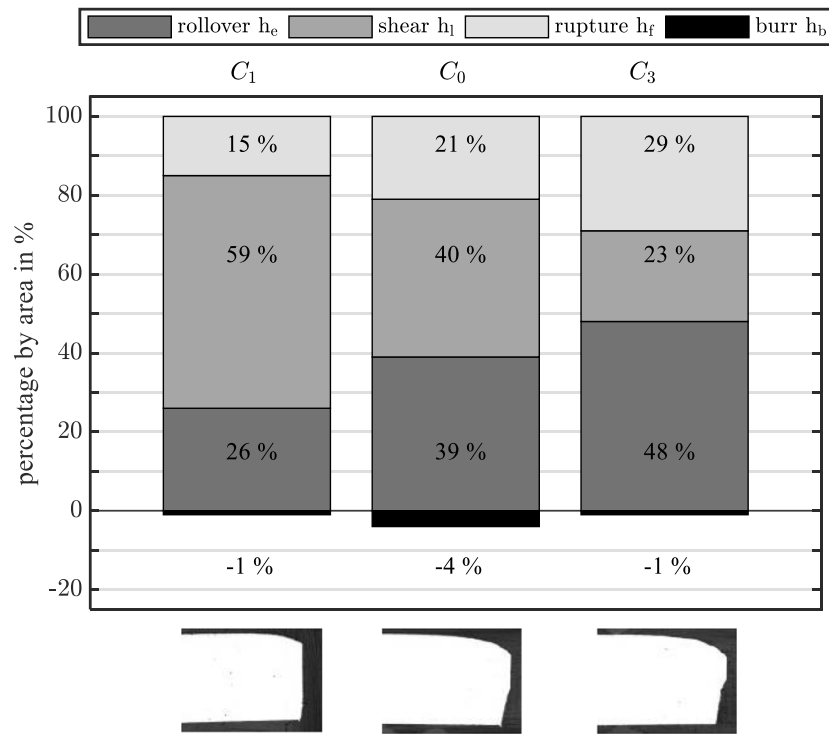

Fig. 12 Percentage allocation of the cutting edge surface depending on the varied parameter clearance $C_{\mathrm{i}}$
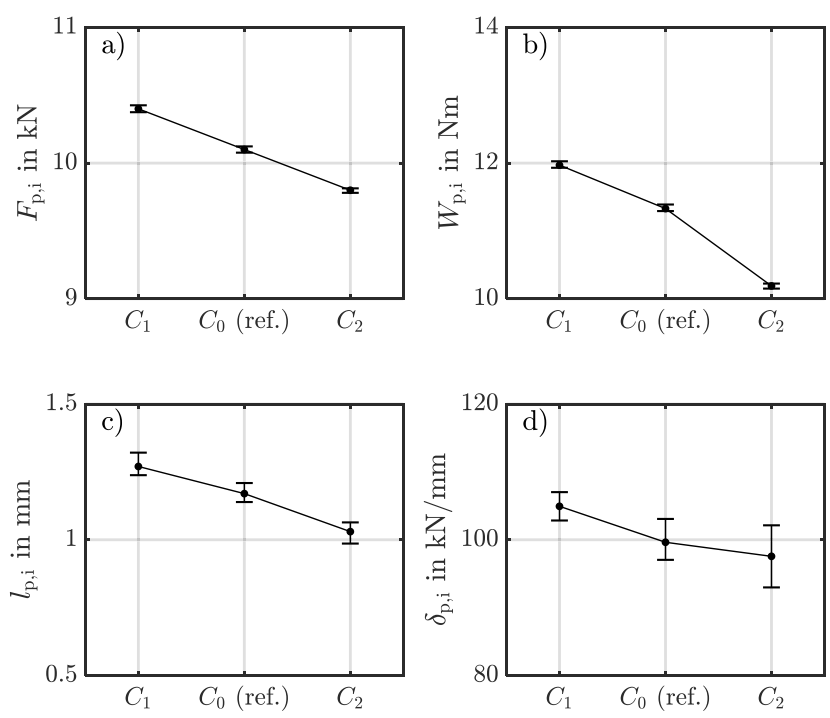

areas of the cutting edge are always related to the current sheet thickness. For example, the ratio of the length of the punchphase to sheet thickness $s_{\mathrm{p}, \mathrm{i}} / s_{\mathrm{i}}$ is approximately the same $(0.5948 \mathrm{~mm} \pm 0.0026 \mathrm{~mm})$. This corresponds to a variation of $\pm 1 \%$ in the rollover zone and $\pm 1.5 \%$ each in percentage of area of the shear and rupture zone.

\subsection{Tensile strength}

In order to vary the material property tensile strength, the semi-finished products were heat-treated. Due to the manufacturing process and the chemical composition of the cold-rolled steel (1.0347), no significant change of the mechanical properties could be detected after the heat-treatment. For this reason, a high-strength steel strip (Rawael ${ }^{\circledR} 80$ ) was used to investigate the influence of varying material properties. As a result of the heat treatment, the dislocation density in the material is reduced and a decrease in strength occurs. The heat treatment was carried out using an annealing program according to Zoch and Spur, which has proven itself many times in practice [47]. During the annealing programs, the holding temperature was varied in the gradations of $550{ }^{\circ} \mathrm{C}$, $600{ }^{\circ} \mathrm{C}, 650^{\circ} \mathrm{C}$, and $700^{\circ} \mathrm{C}$ with a holding time of four hours.

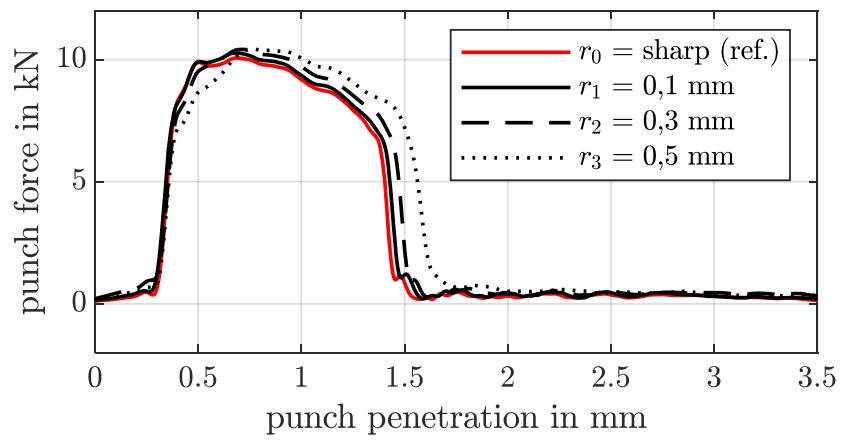

Fig. 13 Force-displacement graph for varying parameter cutting edge radii $r_{\mathrm{i}}$ 
Fig. 14 Features of the punchphase depending on cutting edge radii $r_{\mathrm{i}}$ for maximal force $F_{\mathrm{p}, \mathrm{i}}(\mathbf{a})$, work done $W_{\mathrm{p}, \mathrm{i}}(\mathbf{b})$, length $l_{\mathrm{p}, \mathrm{i}}(\mathbf{c})$, and elastic gradient $\delta_{\mathrm{p}, \mathrm{i}}(\mathbf{d})$

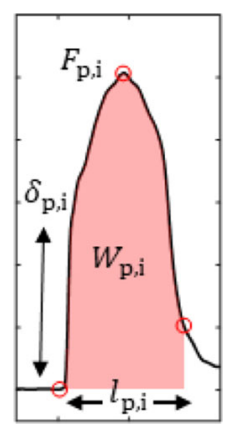

During the holding phase, the material is brought into equilibrium through temperature equalization, which leads to a reduction in tension and tensile strength. In order to determine the tensile strength of the heat-treated specimens, tensile tests were carried out on standardized flat tensile specimens [48]. Figure 19 shows the influence of the heat treatment on the force-displacement curve.

As a result of rising annealing temperatures during heat treatment due to a decrease in tensile strength and an increase in elongation at break, the maximal force and length of the punch-phase are increased. The thermal softening does not change the modulus of elasticity and thus the stiffness of the entire system. As a result, the elastic gradient remains constant but fluctuates around a fixed value caused by statistical uncertainties (Fig. 20). In contrast, the maximal force decreases while the length of punch-phase increases. Soft annealing

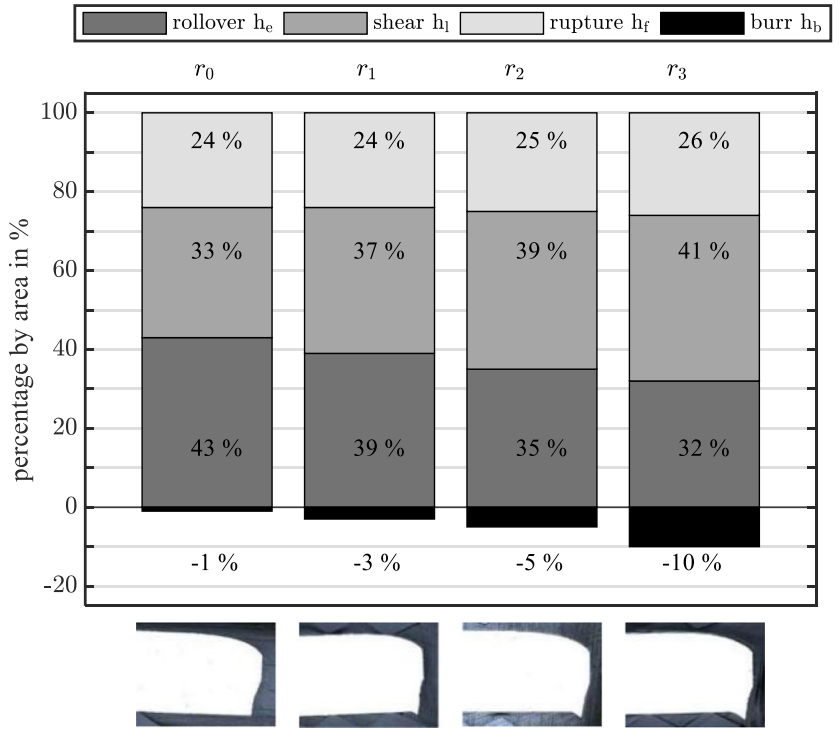

Fig. 15 Percentage allocation of the cutting edge surface depending on the varied parameter clearance $r_{\mathrm{i}}$
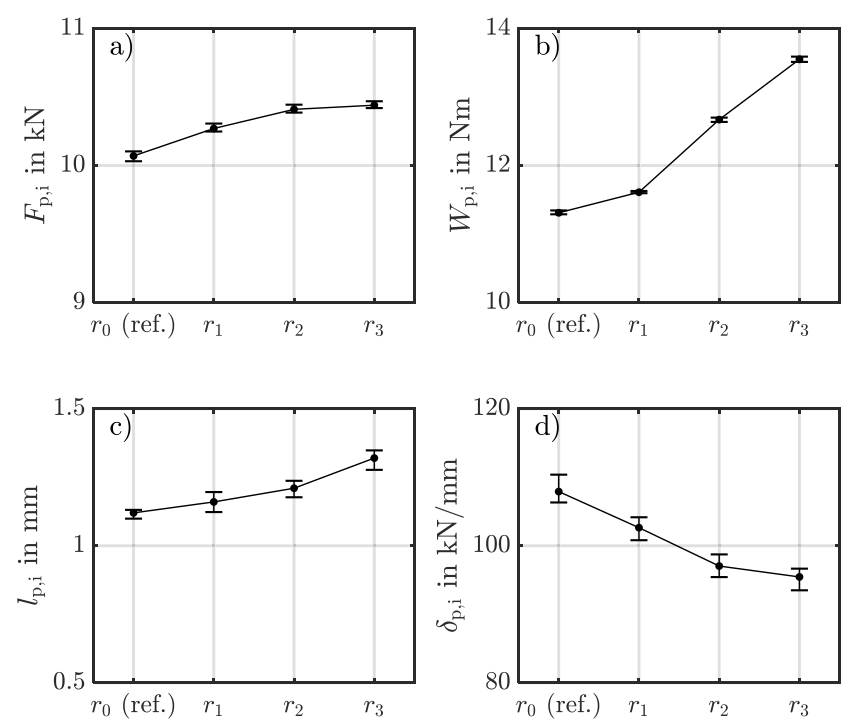

reduces residual stresses caused by the production process and thus leads to a reduction in tensile strength while increasing the elongation at break. This phenomenon results in a local maximum for the work done in the punch-phase. Even if a steady increase of the length of the punch-phase is determined, a reduction of the required work done in this phase is shown. This indicates that the decreasing maximum force is more significant than the extension of the length of the punchphase and therefore the work done in punch-phase has a local maximum.

The evaluation of the cutting edge surface geometry shows a continuous percentage surface increase both in the shear zone and in the rollover zone with simultaneous reduction of the rupture zone (Fig. 21). As a result of the thermal treatment of the semi-finished product, the material softened so that the phase of plastic deformation is extended. Similar to the analysis of the cutting edge radius, this results in a larger burr and a larger shear zone. Furthermore, the softened material forms a larger rollover zone, since the material has a lower yield strength. At the same time, there is an increase of the area in the shear zone and a decrease of the fracture zone [13,20].

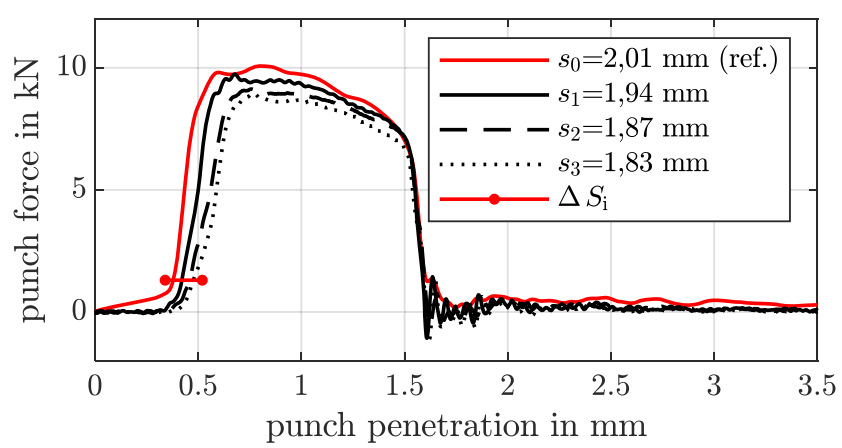

Fig. 16 Force-displacement graph for varying parameter sheet thickness $s_{\mathrm{i}}$ 
Fig. 17 Features of the punchphase depending on sheet thickness $s_{\mathrm{i}}$ for maximal force $F_{\mathrm{p}, \mathrm{i}}(\mathbf{a})$, work done $W_{\mathrm{p}, \mathrm{i}}(\mathbf{b})$, length $l_{\mathrm{p}, \mathrm{i}}(\mathbf{c})$, and elastic gradient $\delta_{\mathrm{p}, \mathrm{i}}(\mathbf{d})$

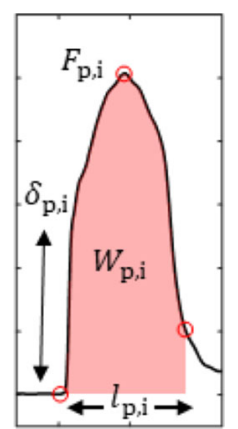

\section{Feature-based correlation between process parameter and quality of the component}

In the previous section, it was shown that feature engineering can be used to uncover property deviations and automatically monitor the current process status. Even small changes in the process can be detected and indicate deficient quality of the component. Therefore, this section presents a decision support for the in-process adjustment in case of erroneously varying process parameters using a regression analysis. Based on the regression coefficient $\beta_{1}$ determined from the linear regression, a decision tree is derived to assist personnel in troubleshooting by identifying erroneous process conditions, the amount of their characteristics, and their cause. According to the work of Traub et al., correlations between these erroneous process states and measured process variables can be derived from regression coefficients [49]. In their work, the authors used a correlation analysis qualitatively describing (strength of the correlation) the cause-effect relation. As soon as there is a strong correlation between process parameter and features, this dependency is assigned the value 1 ; otherwise, there is no influence and the dependency is assigned the value 0 . The correlation between erroneous process conditions and features is therefore only qualitatively described by discrete values. In

Table 3 Shifting of the starting point $S_{\mathrm{i}}$ depending on a reduction in sheet thickness $\Delta s_{\mathrm{i}}$

\begin{tabular}{lll}
\hline $\begin{array}{l}\text { Measured sheet } \\
\text { thickness difference to } \\
\text { reference } \Delta s_{i}=s_{0}-s_{i}\end{array}$ & $\begin{array}{l}\text { Difference of punch- } \\
\text { phase start (features) } \\
\Delta S_{i}=S_{0}-S_{i}\end{array}$ & $\begin{array}{l}\text { Variance of sheet } \\
\text { thickness calculated } \\
\text { from features }\left|\Delta S_{i}-\Delta s_{i}\right|\end{array}$ \\
\hline $0.07 \mathrm{~mm} \pm 0.003 \mathrm{~mm}$ & $0.42 \mathrm{~mm}$ & $\pm 0.0138 \mathrm{~mm}$ \\
$0.14 \mathrm{~mm} \pm 0.003 \mathrm{~mm}$ & $0.46 \mathrm{~mm}$ & $\pm 0.0156 \mathrm{~mm}$ \\
$0.19 \mathrm{~mm} \pm 0.003 \mathrm{~mm}$ & $0.49 \mathrm{~mm}$ & $\pm 0.0262 \mathrm{~mm}$ \\
\hline
\end{tabular}
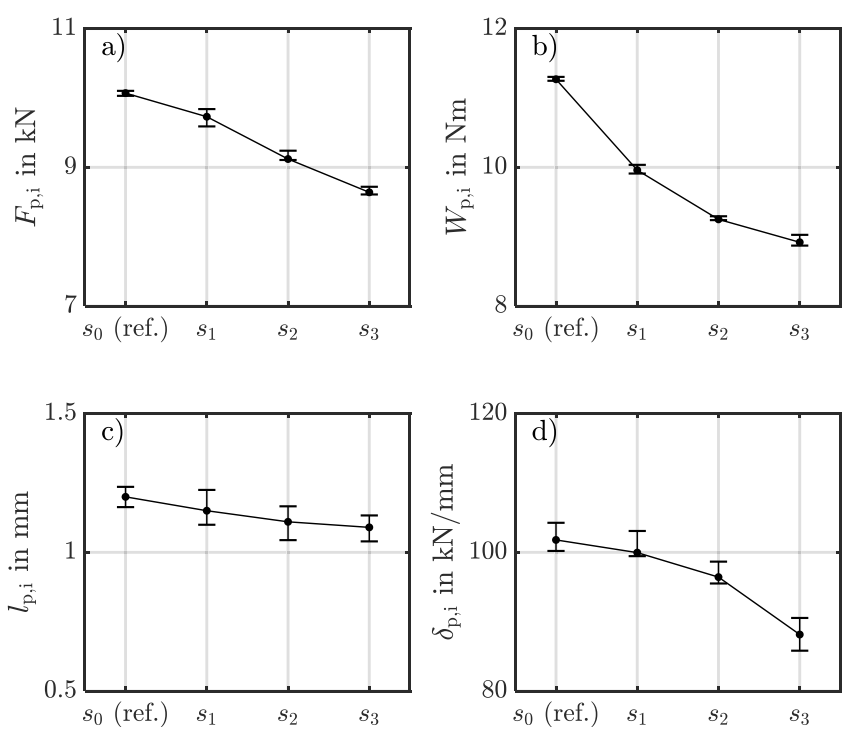

contrast, this work gives a quantitative description of the cause-effect relation (type and form of correlation). This is made possible by the introduction of a decision tree, which contains the quantified dependencies between parameters and features described by the regression coefficient. As soon as changes in the features are detected, it is possible to draw conclusions about the causal parameter based on this decision tree. Qualitative allocation of a varying parameter takes place by considering a positive or negative dependency of the regression coefficient. In the same way, the regression analysis between process parameters and the geometry of the cutting edge surface allow conclusions to be drawn about the quality of the component. By analyzing the property deviations and its effect on the quality of the component, a qualitative decision support for the personnel can be achieved.

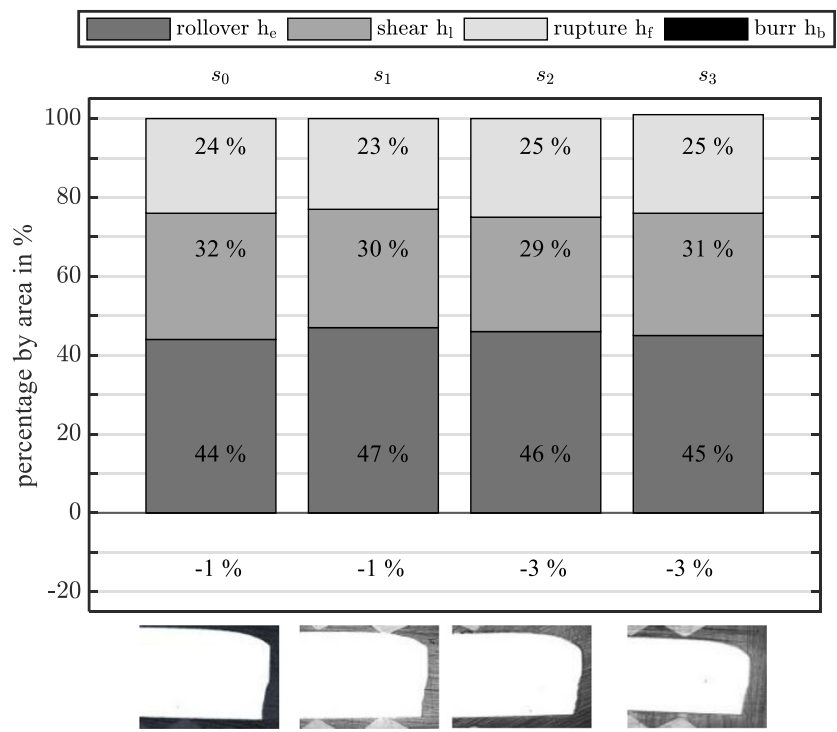

Fig. 18 Percentage allocation of the cutting edge surface depending on the varied parameter clearance $s_{\mathrm{i}}$ 


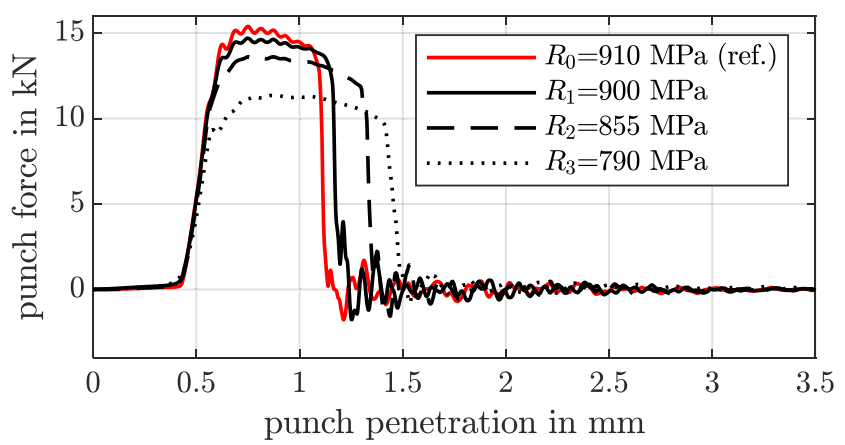

Fig. 19 Force-displacement graph for varying values of the tensile strength $R_{\mathrm{i}}$

In order to establish a quantitative correlation between the cause and its effect, regression analysis is used as the method of choice in this work. In addition, a correlation analysis and the associated determination of the Pearson coefficients are used to show that this correlation can be assumed to be approximately linear. A correlation analysis is performed to show this almost linear relationship between features and varying process parameters. The strength of this linear correlation is explained by the Pearson coefficients [50]. The value of the Pearson coefficient is generally in the range of $R_{\mathrm{xy}} \in[-1,1]$. For coefficients near +1 , there is a strong linear and positive correlation; for values near -1 , there is a strong linear and negative correlation. A value of $R_{\mathrm{xy}}=|1|$ stands for a perfect linear correlation between features (dependent variable) and varying process parameters (independent variable). The Pearson coefficient $R_{x y}$ is calculated by Eq. 3, where $n$ is the number of independent variables of the distribution.

$R_{\mathrm{xy}}=\frac{\sum_{i=1}^{n}\left(x_{i}-\bar{x}\right)\left(y_{i}-\bar{y}\right)}{\sqrt{\sum_{i=1}^{n}\left(x_{i}-\bar{x}\right)^{2}} \sqrt{\sum_{i=1}^{n}\left(y_{i}-\bar{y}\right)^{2}}}$

Fig. 20 Features of the punchphase depending on tensile strength $R_{\mathrm{i}}$ for maximal force $F_{\mathrm{p}, \mathrm{i}}$

(a), work done $W_{\mathrm{p}, \mathrm{i}}(\mathbf{b})$, length $l_{\mathrm{p}, \mathrm{i}}$

(c), and elastic gradient $\delta_{\mathrm{p}, \mathrm{i}}(\mathbf{d})$

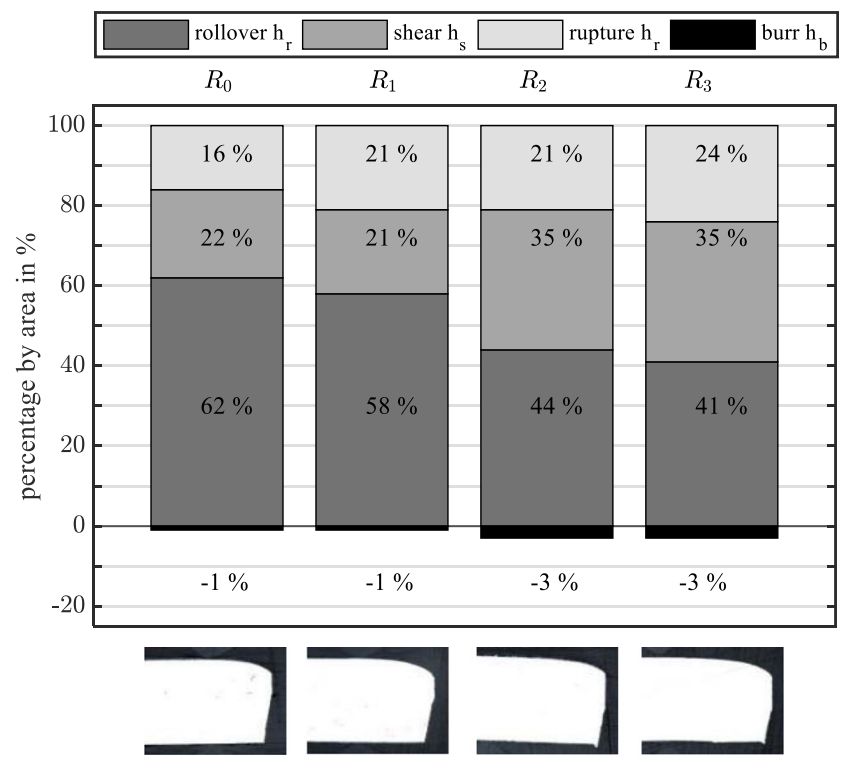

Fig. 21 Percentage allocation of the cutting edge surface depending on the varied parameter tensile strength $R_{\mathrm{i}}$

The calculated coefficients for analyzing the dependencies between features and varying tool and semi-finished product parameters are listed in Table 4. It is shown that there is a strong linear relationship $\left(\left|R_{\mathrm{xy}}\right|>0.87\right)$ for most of the dependencies between tool or semi-finished product parameters and features. Merely the dependency between tensile strength and the work done during the punch phase shows a smaller value at $R_{\mathrm{xy}}=0.83$, but still has to be regarded as a high correlation according to the definition of Cohen [51]. However, there is no correlation between the tensile strength and the elastic gradient. As described in Section 3.4, this is due to the fact that although heat treatment leads to a reduction of the maximum process force and an increase of the cutting phase, it has no influence on the stiffness of the system and therefore does not affect the elastic gradient. It can now be assumed that a
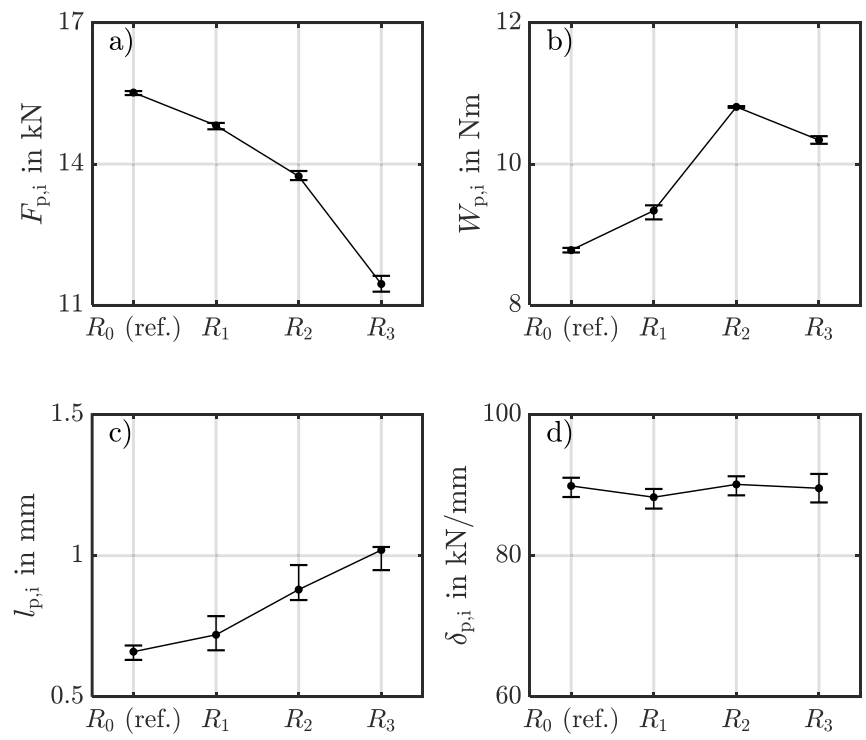
Table 4 Coefficients according to Pearson $R_{\mathrm{xy}}$ and coefficient $\beta_{1}$ of the linear regression model describing the dependencies between tool or semifinished product parameters and features

\begin{tabular}{llllll}
\hline & & Sheet thickness, $s_{\mathrm{i}}$ & Tensile, strength $R_{\mathrm{i}}$ & Clearance, $C_{\mathrm{i}}$ & Cutting edge radii, $r_{\mathrm{i}}$ \\
\hline Maximal force punch-phase $F_{\mathrm{p}}$ & $R_{\mathrm{xy}}$ & +0.9989 & +0.9949 & -0.9993 & +0.9106 \\
& $\beta_{1}$ & +7.5971 & +0.0324 & -0.0749 & +0.6932 \\
Length of punch-phase $l_{\mathrm{p}}$ & $R_{\mathrm{xy}}$ & +0.8770 & -0.9595 & -0.9415 & -0.8965 \\
& $\beta_{1}$ & +0.5825 & -0.0029 & -0.0301 & +0.9979 \\
Work done in punch-phase $W_{\mathrm{p}}$ & $R_{\mathrm{xy}}$ & +0.9940 & +0.8386 & -0.2235 & +0.9789 \\
& $\beta_{1}$ & +12.2820 & -0.0125 & -0.9694 & -0.9926 \\
Elastic gradient punch-phase $\delta_{\mathrm{P}}$ & $R_{\mathrm{xy}}$ & +0.9584 & -0.1678 & +0.9177 & -24.2920 \\
& $\beta_{1}$ & +67.3350 & - & - & -
\end{tabular}

quantitative prediction varying process parameters is permissible by a simple linear regression according to Sieberts et al. [52].

The regression coefficients $\beta_{0}$ and $\beta_{1}$ describe the linear dependency between one feature and one process parameter. In the case presented, the actual value of the process parameter $y$ is defined by a feature $x$ so that the linear regression model is simplified to a linear function as follows:

$y=\beta_{o}+\beta_{1} \cdot x$

with the regression coefficient $\beta_{1}$ describing the quantification of the linear dependency

$\beta_{1}=\frac{\sum_{\mathrm{i}=1}^{\mathrm{n}}\left(x_{\mathrm{i}}-\bar{x}\right)\left(y_{\mathrm{i}}-\bar{y}\right)}{\sum_{\mathrm{i}=1}^{\mathrm{n}}\left(x_{\mathrm{i}}-\bar{x}\right)^{2}}$

Table 4 also shows the regression coefficient $\beta_{1}$ for the dependencies between tool and semi-finished product parameters and features. By determining features from the ongoing process and entering these values into Eq. 4, the current process condition can be described quantitatively. Furthermore,

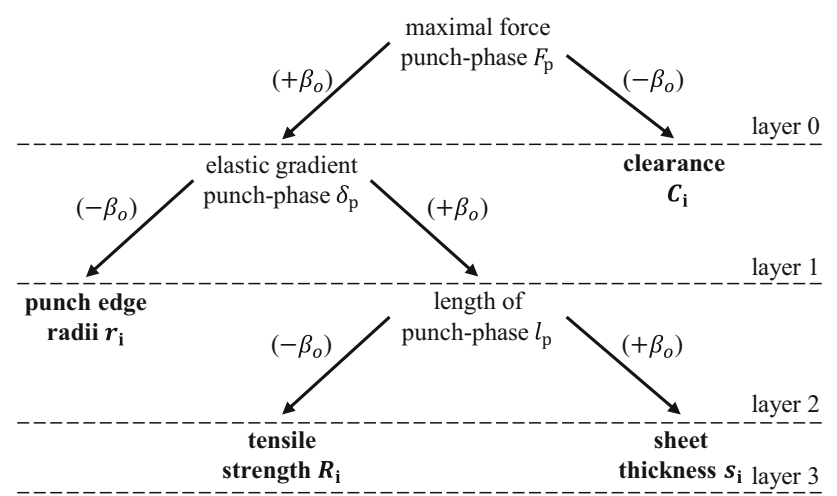

Fig. 22 Multiple decision tree architecture for decision support in for detecting and identifying of property deviations the regression coefficients $\beta_{1}$ serve as hierarchically sequential rules for the decision tree.

The decision tree shown in Fig. 22 provides assistance to the personnel with respect to this purpose. Differentiation is made between a progressive and degressive deviation, between in-process determined features and reference features. The progressive or the degressive deviation is equal to the mathematical sign of the regression coefficient $\beta_{1}$. Due to the fact that the work done in the punch-phase affects all features approximately in the same way and shows a significant redundancy to the maximal punch force, it is not necessary to consider this feature in the decision support by the decision tree [40]. Besides the qualitative detection of the varying process parameters, a quantification of the variation by the regression model is possible. Therefore, quantitative correlations from Section 3 are assigned on the basis of the regression coefficients $\beta_{0}$ and $\beta_{1}$ in each layer of the decision tree.

In order to predict the quality of the component, Table 4 shows the regression coefficient $\beta_{1}$ and the Pearson coefficient $R_{\mathrm{xy}}$ depending on the varying punch and semi-finished product parameters and cutting edge surface parameters. It is shown that especially the cutting edge radii have a significant influence on the geometry of the cutting edge. Similar to Fig. 22 , affected parameters in case of a varying process condition will be detected by changing features. Afterwards, the state of the cutting edge can be derived from the regression coefficients in Table 5.

\section{Validation of feature-based troubleshooting}

In order to verify the feature-based detection of varying process parameters by means of the correlation analysis explained in Section 4, the cause for an erroneous process condition is identified. A worn punch, described by a rounded cutting edge radii, is selected as an example for an erroneous process 
Table 5 Coefficients according to Pearson $R_{\mathrm{xy}}$ and regression coefficient $\beta_{1}$ describing the dependencies between tool or semi-finished product parameters and cutting edge surface parameters

\begin{tabular}{llllll}
\hline & & Rollover zone $h_{\mathrm{e}}$ & Shear zone $h_{\mathrm{l}}$ & Rupture zone $h_{\mathrm{f}}$ & Burr height $h_{\mathrm{b}}$ \\
\hline Sheet thickness, $s_{\mathrm{i}}$ & $R_{\mathrm{xy}}$ & +0.9771 & +0.726 & -0.6691 & +0.8200 \\
& $\beta_{1}$ & -7.7667 & -0.1818 & -0.8003 & -0.0053 \\
Tensile strength, $R_{\mathrm{i}}$ & $R_{\mathrm{xy}}$ & +0.8705 & -0.7931 & +0.8962 & -0.8365 \\
& $\beta_{1}$ & -0.0504 & +1.5606 & -1.2811 & +0.1098 \\
Clearance, $C_{\mathrm{i}}$ & $R_{\mathrm{xy}}$ & +0.9978 & -1.000 & +0.9950 & -0.6500 \\
& $\beta_{1}$ & +1.7419 & -2.5473 & -0.6125 & -0.01635 \\
Cutting edge radii, $r_{\mathrm{i}}$ & $R_{\mathrm{xy}}$ & +0.9033 & +0.4000 & -0.8040 & +0.9473 \\
& $\beta_{1}$ & +4.2372 & +3.6363 & -1.2173 & +0.7672 \\
\hline
\end{tabular}

condition. The following test data set, in which several process parameters are changed simultaneously, is used to show that the detection of an erroneous process condition is also possible under industry-related conditions. Within the test data set, a rounded cutting edge radius with simultaneous variation of the sheet thickness shall be detected. The procedure for detecting the error is shown in Fig. 23. Force-displacement curves are recorded from the blanking process and features are identified. These features are compared with reference features values of the targeted state and as a result the regression factor $\beta_{1}$ is determined. With this method, a qualitative analysis of the causes for varying process parameters (erroneous process condition) and the amount of deviation from the reference state can be quantified. The decision tree shown in Fig. 22 is used as a support for identifying the cause of the error. Based on the identified property deviation, the personnel receives guidance on how to adapt the process to achieve a targeted state.

Section 4 shows how the regression factor combined with the decision tree allows the identification of property deviations and thus the state of the component. Here, it is assumed that only one parameter varies in the process. To show that an identification of property deviations is even possible by varying of several process parameters, the combined variations shown in Table 6 are examined. A variation of the cutting edge radii $\left(r_{0,1}=0.1 \mathrm{~mm}\right.$ and $\left.r_{0,3}=0.3 \mathrm{~mm}\right)$ with a simultaneous change in sheet thickness $\left(s_{i}=1.85 \mathrm{~mm} \pm 0.016 \mathrm{~mm}\right)$ is to be identified. For comparison, the reference condition with a sharp cutting edge radius $r_{0}$ and the initial sheet thickness $s_{0}=2.01 \mathrm{~mm} \pm 0.01 \mathrm{~mm}$ is used. Figure 24 shows the force-displacement curves for combined varying values of the cutting edge radii $r_{i}$ and sheet thickness $s_{i}$.
Due to an increased sheet thickness, it can be seen that the punch-phase of the reference condition starts to occur at a former stage during the downward stroke. Furthermore, the combined variations show an extension of the cutting phase with increasing rounding of the cutting edge. This corresponds to the findings of Sections 3.3 and 3.2. Looking at the features for the three combined states, as shown in Table 6 and Fig. 25, it becomes clear that only the elastic gradient shows a clear linear trend.

As already demonstrated, the rounded cutting edge radius results in a reduction of the cutting line. This affects the stiffness of the system comprising sheet metal and tool. In contrast, there is no clear trend to recognize between the maximum force and, accordingly, in the work done during the punch-phase and the length of the punch-phase. As a result of the rounded cutting edge radii, the length of the punchphase increases (see Fig. 14). However, this effect is compensated by a reduction of the punch-phase length due to a reduced sheet thickness (see Fig. 17). A similar effect can be observed for the maximum force during the punch-phase. In contrast, the cutting force increases with increasing cutting edge radius but decreases due to reduced sheet thickness. However, with increasing cutting edge radii, the maximal force rises, but in contrast to this, a reduction of the maximal force is induced due to reduced sheet thickness. The results indicate that a combined variation of process parameters no longer provides an unambiguous correlation between the features in the punch-phase and a changed process state as suggested in Section 4. This leads to the conclusion that an identification of the variation of the cutting edge radii shown in this example is no longer possible using the decision tree shown in Fig. 22. Due to the positive sign of the regression
Fig. 23 Procedure for detecting erroneous process condition

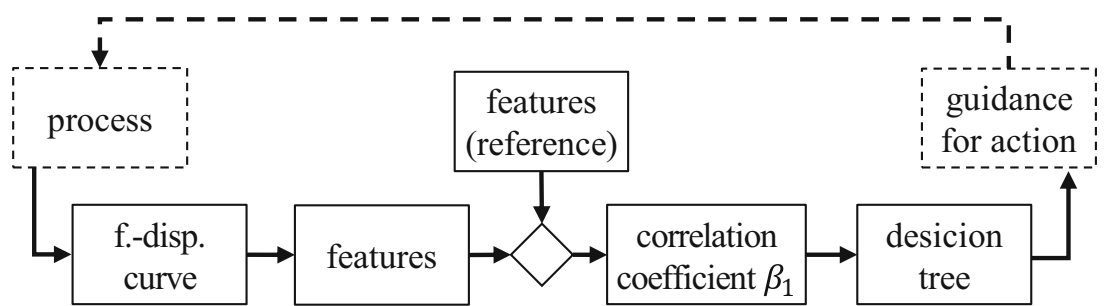


Table 6 Features of punch-phase extended by feature of withdraw-phase for combined varying values of the cutting edge radii $r_{\mathrm{i}}$ and sheet thickness $s_{\mathrm{i}}$

\begin{tabular}{|c|c|c|c|c|}
\hline & $\begin{array}{l}\text { Ref. } \\
s_{0}=2.01 \mathrm{~mm} \\
r_{0}=\text { sharp }\end{array}$ & $\begin{array}{l}\text { Com. A } \\
s_{0}=1.85 \mathrm{~mm} \\
r_{0}=\text { sharp }\end{array}$ & $\begin{array}{l}\text { Com. B } \\
s_{0}=1.85 \mathrm{~mm} \\
r_{0}=0.10 \mathrm{~mm}\end{array}$ & $\begin{array}{l}\text { Com. C } \\
s_{0}=1.85 \mathrm{~mm} \\
r_{0}=0.30 \mathrm{~mm}\end{array}$ \\
\hline Maximal force punch-phase, $F_{\mathrm{p}}$ & $10.05 \mathrm{kN}$ & $9.22 \mathrm{kN}$ & $9.52 \mathrm{kN}$ & $9.76 \mathrm{kN}$ \\
\hline Length of punch-phase, $l_{\mathrm{p}}$ & $1.24 \mathrm{~mm}$ & $1.01 \mathrm{~mm}$ & $1.09 \mathrm{~mm}$ & $1.33 \mathrm{~mm}$ \\
\hline Elastic gradient punch-phase, $\delta_{\mathrm{P}}$ & $105.88 \frac{\mathrm{kN}}{\mathrm{mm}}$ & $104.3 \frac{\mathrm{kN}}{\mathrm{mm}}$ & $99.67 \frac{\mathrm{kN}}{\mathrm{mm}}$ & $92.16 \frac{\mathrm{kN}}{\mathrm{mm}}$ \\
\hline Work done in punch-phase $W_{\mathrm{p}}$ & $11.74 \mathrm{Nm}$ & $9.81 \mathrm{Nm}$ & $10.74 \mathrm{Nm}$ & $12.62 \mathrm{Nm}$ \\
\hline Maximal force-withd.-phase $F_{\mathrm{w}}$ & $0.011 \mathrm{kN}$ & $0.009 \mathrm{kN}$ & $-0.198 \mathrm{kN}$ & $-0.458 \mathrm{kN}$ \\
\hline Work done in withd.-phase $W_{\mathrm{w}}$ & $-0.07 \mathrm{Nm}$ & $-0.02 \mathrm{Nm}$ & $-0.93 \mathrm{Nm}$ & $-1.67 \mathrm{Nm}$ \\
\hline
\end{tabular}

coefficient $\beta_{1}$. in layer 0 , it is assumed that an increase of the maximal force can be determined by the rounding of the cutting edge. In the present case of the combined varied cutting edge radii, on the contrary, a degressive trend can be seen. As shown in Fig. 25, the maximal force decreases even if the cutting edge radii are increased. A clear identification of the regression coefficient and its sign is therefore impossible. In this case, it is necessary to add another layer to the decision tree as shown in Fig. 27.

In this additional layer, the features of the punch-phase are extended by features from the withdraw-phase. Also, in this case the length, minimum force and the work done in this phase are defined as features. The features show that a rounded cutting edge leads to a decrease of the minimum force and as a consequence to an increase of absolute work done during the withdraw-phase. This confirms the results of Hohmann, Schatz and Groche which identified a correlation between abrasive wear on the cutting edge and work done during the withdraw-phase as well as a correlation between adhesive wear on the outer surface of the punch and the length of withdraw-phase [8]. Figure 26 illustrates these results and shows an increase in the work done as a result of increasing cutting edge radii. Since new types of punches with a defined cutting edge radii were used in this work, no adhesive wear of the outer surface is to be expected and thus an extension of the withdraw-phase is not detectable.

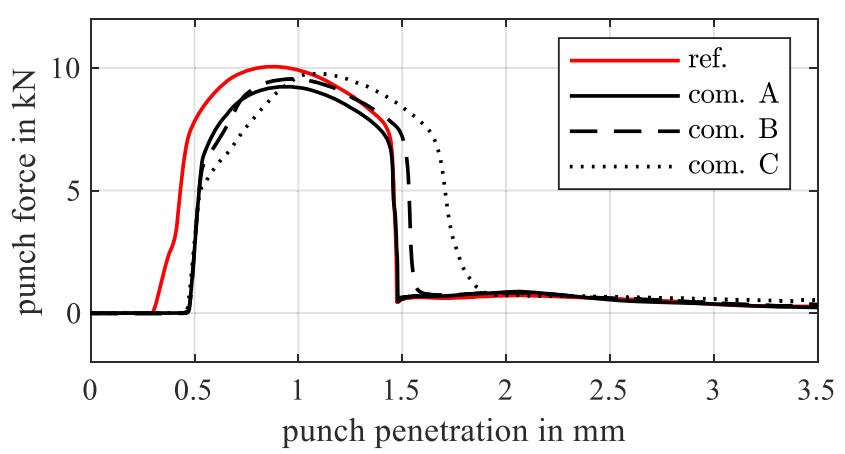

Fig. 24 Force-displacement curve for combined varying values of the cutting edge radii $r_{\mathrm{i}}$ and sheet thickness $s_{\mathrm{i}}$
If the decision tree is now extended by an additional layer (original layer 0 is extended to layer $0^{\prime}$ and layer $0^{\prime \prime}$ ), the cutting edge radii can be identified even if several process parameters are varied. Therefore, a verification is made in the first layer whether there is an influence on the withdrawphase. If the amount of the regression coefficient $\left|\beta_{1}\right|>2$, it is assumed that the cutting edge radius is rounded and an influence on the withdraw-phase can be seen. The threshold corresponds to the work done in the withdraw-phase related to the rounded cutting edge radii. In experiments, it could be shown that a cutting edge radii of $r_{\exp }=0.01 \pm 0.0025 \mathrm{~mm}$ is assumed when work done in the withdraw-phase $\left|W_{W}\right|<0.02 \mathrm{Nm}$. This leads to threshold of the regression coefficient $\left|\beta_{1}\right|$ shown in Eq. 6:

$\left|\beta_{1}\right| \approx \frac{W_{W}}{r_{\exp }} \approx 2$

Afterwards, an if-then analysis can be performed as usual in the decision tree in layer 1 . With the example shown here of the combined varied process parameters cutting edge radii and sheet thickness, a decrease of the elastic gradient can be detected. This allows a clear identification of the cutting edge radii as the cause for the deviation of the force displacement compared with the reference condition. Furthermore, the absolute value of the regression factor for the work performed in the withdraw-phase can be used to quantify the amount of wear on the cutting edge (Fig. 27).

\section{Summary and outlook}

In this study, force-displacement curves were recorded in a blanking process to derive correlations between varying process parameters and quality features of the component. For this purpose, a feature engineering approach was used to extract features from force-displacement curves and to correlate them with process parameters. Those results serve as a base to determine the current state of the quality of the component. Using coefficients from linear regression, explicit 
Fig. 25 Features of punch-phase extended by feature of withdrawphase for combined varying values of the cutting edge radii $r_{\mathrm{i}}$ and sheet thickness $s_{\mathrm{i}}$
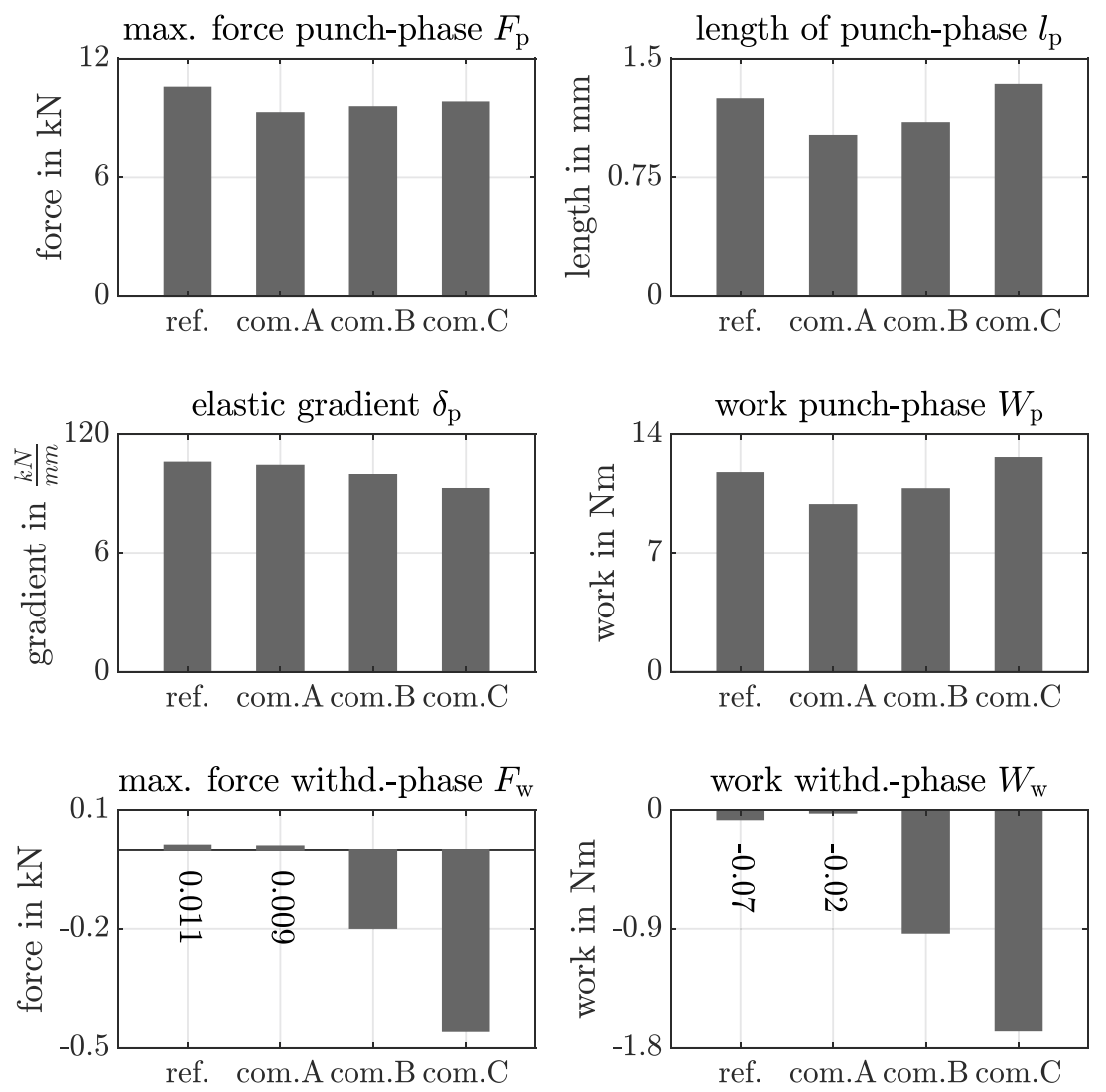

dependencies between features and process parameters and their physical cause could be established. Additionally, this regression provides a model to describe quantitatively the correlations between features und erroneous process conditions. Even small variations of the tool and semi-finished product parameters within a range of a few percent compared with the initial state, as they occur in industrial production, could be detected.

Results of this study showed that the identification of features plays a crucial role. By using a process-driven approach of feature engineering, features were reliably detected even at high stroke rates and within small parameter variations. It was shown that features on the one hand reduce the amount of data

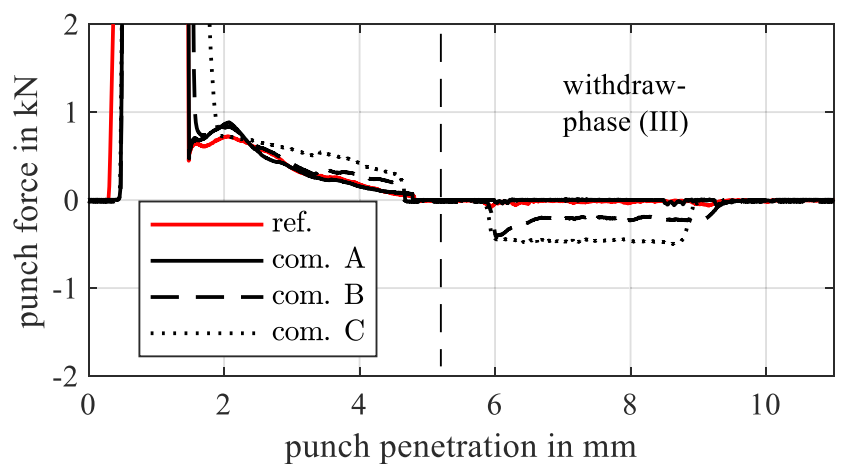

Fig. 26 Detailed view of withdraw-phase in force-displacement graph for combined varying values of the cutting edge radii $r_{\mathrm{i}}$ and sheet thicknes $s_{\mathrm{i}}$ without any loss of relevant information and on the other hand are able to describe property deviations during blanking. This allows to monitor the current condition of the tool and semifinished product parameters as well as the quality of the cutting edge surfaces.

Furthermore, it could be shown that the method presented allows the detection of the property deviations even if several process parameters are varied simultaneously. For this purpose, the features of the punch-phase were extended by the

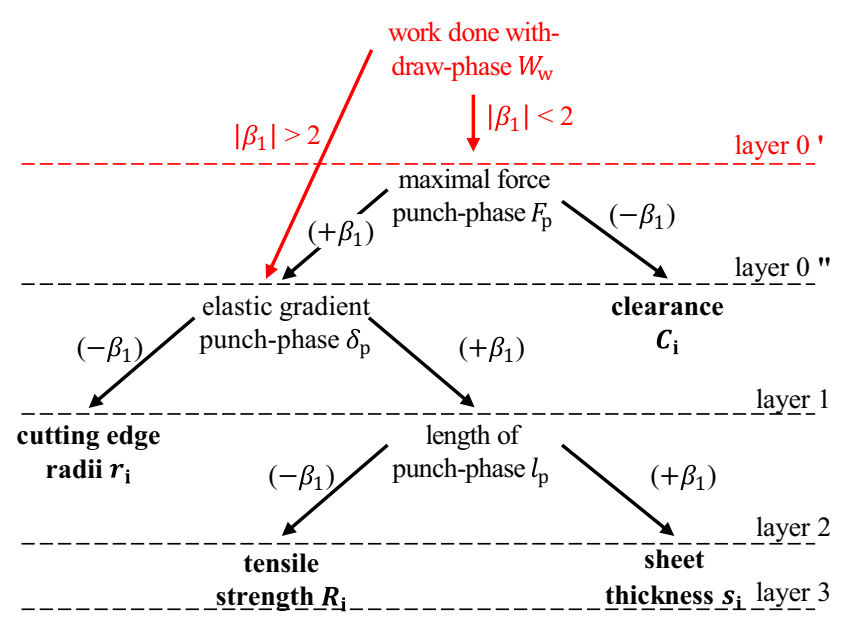

Fig. 27 Extended multiple decision tree architecture for decision support in detecting and identifying of property deviations for combined varying process parameters 
features of the withdraw-phase. In addition to the detection of the error cause, a prediction about the degree of wear could be made. This finding allows the conclusion that an extension of the features can significantly improve the identification of deficient process and component states. The following studies must therefore clarify which additional features, e.g., during push-phase, can increase the benefits of the current process monitoring system. On the other hand, it is necessary to clarify how data-induced conflicts, e.g., caused by faulty sensor signals, affect the resilience of property deviations.

Further methods are required to investigate the influence of multiple tool or semi-finished product parameters on the process. It also has to be clarified how dynamic effects influence the extraction of features and how reliable they are to monitor the current process conditions even at high stroke rates.

Acknowledgments The authors wish to thank for funding and supporting this project. Furthermore, the authors sincerely thank Bruderer AG for providing the high-speed press BSTA 810-145 and Kistler AG for providing measurement equipment to record sets of data even under challenging circumstances.

Author contributions All authors contributed equally to the work.

Funding Open Access funding enabled and organized by Projekt DEAL. The research leading to these results received funding from Federal Ministry of Economics and Energy - Collaborative Project: Mittelstand Kompentenzzentrum 4.0 Darmstadt under Grant Agreement No. 01MF15005A.

Data availability The authors guarantee no restriction of availability of data, material, and code.

\section{Compliance with ethical standards}

Conflict of interest The authors declare that they have no conflict of interest.

Ethical approval This article does not contain any studies with human participants or animals performed by any of the authors.

Consent to participate Informed consent was obtained from all individual participants included in the study.

Consent to publish The publisher has the permission of the authors to publish the given article.

Open Access This article is licensed under a Creative Commons Attribution 4.0 International License, which permits use, sharing, adaptation, distribution and reproduction in any medium or format, as long as you give appropriate credit to the original author(s) and the source, provide a link to the Creative Commons licence, and indicate if changes were made. The images or other third party material in this article are included in the article's Creative Commons licence, unless indicated otherwise in a credit line to the material. If material is not included in the article's Creative Commons licence and your intended use is not permitted by statutory regulation or exceeds the permitted use, you will need to obtain permission directly from the copyright holder. To view a copy of this licence, visit http://creativecommons.org/licenses/by/4.0/.

\section{References}

1. Demmel P, Nothhaft K, Golle R (2012) Zerteilen, Handbuch Umformen, Kapitel 10, p 679-729.

2. (2020) Metal stamping market size, share \& trends report metal stamping market size, share $\&$ trends analysis report by process (blanking, embossing), by application (automotive, industrial machinery, consumer electronics), by region, and segment forecasts, 2020-2027. https://www.grandviewresearch.com/industryanalysis/metal-stamping-market. Accessed 26 Jul 2020

3. Berger R (2012) Mastering product complexity.

4. Weck M (2006) Werkzeugmaschinen 3 - Mechatronische Systeme, Vorschubantriebe, Prozessdiagnose, VDI-Verlag Düsseldorf.

5. Klocke F, Kamps S, Mattfeld P, Shirobokov A et al (2017) Assisstenzsysteme in der Produktionstechnik, Virtuelle Instrumente in der Praxis, Begleitband zum 22. VIP-Kongress, $p$ 265-288

6. Hambli R (2002) Design of experiment based analysis for sheet metal blanking processes optimisation. Int J Adv Manuf Technol 19(6):403-410

7. Jin J, Shi J (2000) Diagnostic feature extraction from stamping tonnage signals based on design of experiments. J Manuf Sci Eng 122(2):360-369

8. Hohmann J, Schatz T, Groche P (2017) Intelligent wear identification based on sensory inline information for a stamping process. In: Majstorovic V, Jakovljevic Z (eds) Proceedings of 5th International Conference on Advanced Manufacturing Engineering and Technologies. NEWTECH 2017. Lecture Notes in Mechanical Engineering. Springer, Cham

9. Lange K (1985) Handbook of metal forming. McGraw-Hill, New York

10. Romanowski WP (1965) Handbuch der Stanztechnik. VEB Verlag Technik, Berlin

11. Oehler G, Kaiser F (1993) Schnitt-, Stanz- und Ziehwerkzeuge. Springer, Berlin Heidelberg

12. Maeda T, Matsuno K (1967) Wear on shearing tools: wear on cutting edges of blanking tool for square parts. JSME 10(37): 197-205

13. Feistle M, Koslow I, Krinninger M, Golle R, Volk W (2017) Reduction of burr formation for conventional shear cutting of boron-alloyed sheets through focused heat treatment. Procedia CIRP 63:493-498

14. Hoogen M (1999) Einfluß der Werkzeuggeometrie auf das Scherschneiden und Reißen von Aluminiumfeinblechen, Dissertation, Technischen Universität München.

15. Koh CKH, Shi J, Black J (1996) Tonnage signature attribute analysis for stamping process. NAMRI/SME (23):193-198

16. Salfeld V, Matthias T, Krimm R, Behrens BA (2012) Analysis of machine influence on process stability in sheet bulk metal forming. Procedia CIRP 3:32-36

17. Timmerbeil F-W (1956) Untersuchung des Schneidvorgangs bei Blech, insbesondere beim geschlossenen Schnitt, Dissertation.

18. Zafer T, Muammer N, Gürün H (2006) An experimental study for the effect of different clearances on burr, smooth-sheared and blanking force on aluminium sheet metal. Mater Des 27(10): 1134-1138

19. Hambli R, Guerin F, Dumon B (2003) Numerical evaluation of the tool wear influence on metal-punching processes. Int J Adv Manuf Technol 21(7):483-493

20. Gréban F, Monteil G, Roizard X (2007) Influence of the structure of blanked materials upon the blanking quality of copper alloys. J Mater Process Technol 186(1-3):27-32

21. Breitling J, Pfeiffer B, Altan T et al (1997) Process control in blanking. JMPT 71(1):187-192 
22. Groche P, Hohmann J, Übelacker D (2019) Overview and comparison of different sensor positions and measuring methods for the process force measurement in stamping operations. Measurement 135:122-130

23. Roskam R (1999) In-Prozeß-Überwachung von Pressen der Blechverarbeitung, Dissertation.

24. Jemielniak K (1999) Commercial tool condition monitoring systems. Int J Adv Manuf Technol 15(10):711-721

25. Ge M, Du R, Zhang G et al (2002) Fault diagnosis using support vector machine with an application in sheet metal stamping operations. Mech Syst Signal Process 18(1):143-159

26. Koh CKH, Shi J, Williams WJ, Ni J (1999) Multiple fault detection and isolation using the Haar transform, part 2: application to the stamping process. J Manuf Sci Eng 121(2):295-299

27. Lee WB, Cheung CF, Chiu WM, Chan LK (1997) Automatic supervision of blanking tool wear using pattern recognition analysis. Int J Mach Tools Manuf 37(8):1079-1095

28. Jin J, Shi J (2001) Automatic feature extraction of waveform signals for in-process diagnostic performance improvement. J Intell Manuf 12(3):257-268

29. Krüger J, Fleischer J, Franke J et al (2019) KI in der Produktion Künstliche Intelligenz erschliessen für Unternehmen

30. German Institute for Standardization (2006) DIN EN 10140: Cold rolled narrow steel strip - Tolerances on dimensions and shape.

31. German Institute for Standardization (2007) DIN EN 10130: Cold rolled low carbon steel flat products for cold forming - technical delivery conditions

32. Hirsch MJ (2012) Einfluss von Leichtbauwerkstoffen in schnelllaufenden Stanzwerkzeugen auf das Verschleißverhalten, Dissertation

33. Klingenberg W, de Boer TW (2008) Condition-based maintenance in punching/blanking of sheet metal. Int J Mach Tools Manuf 48(5): 589-598

34. Slavič J, Bolka Š, Bratuš V, Boltežar M (2014) A novel laboratory blanking apparatus for the experimental identification of blanking parameters. J Mater Process Technol 214(2):507-513

35. Hernández JJ, Franco P, Estrems M et al (2006) Modelling and experimental analysis of the effects of tool wear on form errors in stainless steel blanking. J Mater Process Technol 180(1-3):143-150

36. Falconnet E, Makich H, Chambert J et al (2012) Numerical and experimental analyses of punch wear in the blanking of copper alloy thin sheet. Wear 296(1-2):598-606

37. German Institute for Standardization (2011) DIN EN ISO 376: metallic materials - calibration of force-proving instruments used for the verification of uniaxial testing machines.

38. Veenstra PC, Ramaekers JAH (1978) A criterion for critical tool wear in blanking. CIRP Ann 27:157-158
39. Budnik M, Gutierrez-Gomez E-L, Safadi B, Pellerin D, Quénot G (2017) Learned features versus engineered features for multimedia indexing. Multimed Tools Appl 76(9):11941-11958

40. Hoppe F, Hohmann J, Knoll M, Kubik C, Groche P (2019) Featurebased supervision of shear cutting processes on the basis of force measurements: evaluation of feature engineering and feature extraction. Procedia Manuf 34:847-856

41. Übelacker D (2018) Vorgehensweise zur Gestaltung phasenorientierter Prozesskraftüberwachungssysteme für Umformprozesse, Dissertation

42. Taupin E, Breitling J, Wu W-T et al (1996) Material fracture and burr formation in blanking results of FEM simulations and comparison with experiments. J Mater Process Technol 59(1-2):68-78

43. Klingenberg W, Singh UP (2004) Principles for on-line monitoring of tool wear during sheet metal punching. In: Hinduja S (ed) Proceedings of the 34th International MATADOR Conference. Springer, London

44. Hambli R (2002) Prediction of burr height formation in blanking processes using neural network. Int J Mech Sci 44(10):2089-2102

45. Makich H, Carpentier L, Monteil G et al (2008) Metrology of the burr amount - correlation with blanking operation parameters (blanked material - wear of the punch). Int J Mater Form 1(S1): 1243-1246

46. Doege E, Behrens B-A (2010) Handbuch Umformtechnik. Springer, Berlin

47. Zoch H-W, Spur G (2015) Handbuch Wärmebehandeln und Beschichten. Carl Hanser Fachbuchverlag

48. German Institute for Standardization (2016) DIN 50125: testing of metallic materials - tensile test pieces

49. Traub T, Gregório MG, Groche P (2018) A framework illustrating decision-making in operator assistance systems and its application to a roll forming process. Int J Adv Manuf Technol 97(9-12):37013710

50. Pearson K (1985) Note on regression and inheritance in the case of two parents. Proc R Soc Lond 58:240-242. JSTOR. www.jstor.org/ stable/115794. Accessed 12 Jul 2020

51. Cohen J (2013) Statistical power analysis for the behavioral sciences. Elsevier Science, Burlington. http://gbv.eblib.com/patron/ FullRecord.aspx? $\mathrm{p}=1882849$. Accessed 2 Oct 2020

52. Siebertz K, van Bebber D, Hochkirchen T (2017) Statistische Versuchsplanung. Springer, Berlin

Publisher's note Springer Nature remains neutral with regard to jurisdictional claims in published maps and institutional affiliations. 